\title{
Modes and Models of Forebrain Cholinergic Neuromodulation of Cognition
}

\author{
Michael E Hasselmo*, ${ }^{*}$ and Martin Sarter ${ }^{2}$ \\ ${ }^{1}$ Center for Memory and Brain, Department of Psychology and Program in Neuroscience, Boston University, Boston, MA, \\ USA; ${ }^{2}$ Department of Psychology and Neuroscience Program, University of Michigan, Ann Arbor, MI, USA
}

\begin{abstract}
As indicated by the profound cognitive impairments caused by cholinergic receptor antagonists, cholinergic neurotransmission has a vital role in cognitive function, specifically attention and memory encoding. Abnormally regulated cholinergic neurotransmission has been hypothesized to contribute to the cognitive symptoms of neuropsychiatric disorders. Loss of cholinergic neurons enhances the severity of the symptoms of dementia. Cholinergic receptor agonists and acetylcholinesterase inhibitors have been investigated for the treatment of cognitive dysfunction. Evidence from experiments using new techniques for measuring rapid changes in cholinergic neurotransmission provides a novel perspective on the cholinergic regulation of cognitive processes. This evidence indicates that changes in cholinergic modulation on a timescale of seconds is triggered by sensory input cues and serves to facilitate cue detection and attentional performance. Furthermore, the evidence indicates cholinergic induction of evoked intrinsic, persistent spiking mechanisms for active maintenance of sensory input, and planned responses. Models have been developed to describe the neuronal mechanisms underlying the transient modulation of cortical target circuits by cholinergic activity. These models postulate specific locations and roles of nicotinic and muscarinic acetylcholine receptors and that cholinergic neurotransmission is controlled in part by (cortical) target circuits. The available evidence and these models point to new principles governing the development of the next generation of cholinergic treatments for cognitive disorders.

Neuropsychopharmacology Reviews (2011) 36, 52-73; doi: I 0. 1038/npp.20 I 0. I04; published online 28 July 2010
\end{abstract}

Keywords: acetylcholine; cognition; attention; encoding; cortex; hippocampus

\section{INTRODUCTION}

The entire cortex and hippocampus are innervated by cholinergic projections that originate from several regions in the basal forebrain (Rye et al, 1984; Lysakowski et al, 1989; Mesulam et al, 1992; Kitt et al, 1994). The anatomical organization of this neuronal system predicts that abnormalities in cholinergic activity profoundly impairs cortical and hippocampal information processing (eg, Bartus, 2000; Mesulam, 2004; Sarter et al, 2005a). Consequently, attempts to treat cognitive symptoms and disorders have extensively focused on cholinomimetic strategies.

The traditional description of the forebrain cholinergic system as a diffusely organized neuromodulator system suggests that a relatively small number of neurons show widespread influence on information processing across

${ }^{*}$ Correspondence: Dr ME Hasselmo, Center for Memory and Brain, Department of Psychology and Program in Neuroscience, Boston University, Boston, MA 02215, USA, Tel: +1617353 1397,

E-mail: hasselmo@bu.edu or msarter@umich.edu

Received 1 March 2010; revised 18 June 2010; accepted 19 June 2010 large portions of the cortex and hippocampus. However, we will point out that recent evidence supports an alternative hypothesis, proposing that the cognitive functions of cholinergic projections are determined in part by telencephalic circuitry controlling cholinergic synaptic neurotransmission. Such local control of cholinergic activity may imply that the cholinergic system influences target regions in a more specific manner than previously assumed.

Early theories suggested that the cortical cholinergic input system contributes to the induction of 'arousal' and elevates input processing to the level of awareness or consciousness (Wenk, 1989; Woolf, 1991; Perry et al, 1999). Although recent research indicated that specific cognitive operations are mediated by precisely orchestrated and spatially restricted changes in cholinergic neurotransmission, our current model integrates multiple roles and neurotransmission modes of forebrain cholinergic systems, including the modulation of more global states of target regions as well as the mediation of highly selective cognitive operations. Collectively, these states and cognitive 
operations support attentional performance and the encoding of new information (as illustrated in Figure 2).

In this article, we will explore specifically the effect of more recent findings on the cholinergic mediation of cognitive operations for the development of novel neuropsychopharmacological treatment strategies. We will describe a circuit-based model that is designed to capture key elements of the current evidence and associated hypotheses. The new evidence and this model, together with a model derived from the neurophysiological evidence on the effects of cholinergic modulation, form the basis for new treatment strategies that venture beyond the traditional cholinomimetic mechanisms targeted by acetylcholinesterase (AChE) inhibitors and nonselective muscarinic and nicotinic acetylcholine receptor $(\mathrm{m} / \mathrm{nAChR})$ agonists.

\section{OVERVIEW OF CHOLINERGIC NEUROPSYCHOPHARMACOLOGY}

Early psychopharmacological studies of the role of cholinergic systems in cognition were conducted, to name a few, by Giancarlo Pepeu, David M Warburton, J Anthony Deutsch, and David A Drachman (eg, Pazzagli and Pepeu, 1965; Deutsch and Rocklin, 1967; Deutsch, 1971; Warburton and Brown, 1971; Drachman, 1977; Drachman and Sahakian, 1980). Then and now, this research has depended mainly on the availability of three groups of cholinergic drugs for studies in humans and animals: AChE inhibitors, nonspecific $\mathrm{mAChR}$ antagonists (scopolamine and atropine), and the non-selective nAChR agonist nicotine. The interpretation of the cognitive effects of these drugs has rarely taken into account the enormous complexity of their effects on cholinergic neurotransmission.

AChE inhibitors have been shown to enhance cognitive performance (Aigner and Mishkin, 1986; Aigner et al, 1987) and to reduce the impairments caused by $\mathrm{mAChR}$ antagonists (Ghoneim and Mewaldt, 1977). However, the consequences of sustained, high levels of extracellular ACh levels include the excessive stimulation of presynaptic M2 receptors. Stimulation of these receptors inhibits the release of ACh and thereby attenuates presynaptic signaling. Furthermore, the presence of extremely high concentrations of ACh in the extrasynaptic space (volume transmission) results in the stimulation of extrasynaptic mAChRs (Yamasaki et al, 2010) and nAChRs, to a degree and at locations that may not be achieved in the absence of an AChE inhibitor (Sarter et al, 2009a). Even within the constraints of classic synapses, high levels of ACh are expected to excessively stimulate nAChRs that in turn stimulate the release of several neuromodulators, including $\mathrm{ACh}$ itself, thereby robustly modulating the state of local circuitry (eg, Sarter et al, 2009b). Thus, AChE inhibitors do not merely increase cholinergic neurotransmission but they also uncouple presynaptic from postsynaptic information transmission and produce complex changes in local and efferent circuitry.
With respect to the nonselective $\mathrm{mAChR}$ antagonists, atropine and scopolamine, these drugs have been shown to impair encoding of new memories (Ghoneim and Mewaldt, 1975, 1977; Aigner et al, 1991) and to impair attention (Wesnes and Warburton, 1984; Broks et al, 1988). However, the attribution of the cognitive effects to blockade of postsynaptic mAChRs must be modified by awareness that these drugs also increase the release of ACh because of presynaptic M2 receptor antagonism (eg, Herzog et al, 2003). As a result, extremely high extracellular ACh levels stimulate nAChRs, and such effects may interact with the blockade of postsynaptic mAChRs to cause rather complex behavioral and cognitive effects. Consistent with such a potential interaction, several studies showed that blockade of nAChRs alone did not affect cognitive performance; however, when administered together with a mAChR antagonist, substantial or significantly greater cognitive impairments were observed (eg, Little et al, 1998; Ellis et al, 2006; Erskine et al, 2004).

The investigation of the cognitive effects of nicotine has given rise to an enormously productive field of research on the cognitive functions of nAChRs (eg, Warburton and Mancuso, 1998; Stolerman et al, 2000; Levin et al, 1998; Levin et al, 2006). As will be pointed out below, recent evidence identified the nAChR subtypes that may be of central interest for pharmacological strategies aimed at enhancing attentional performance effects. Furthermore, research on the role of these subtypes has begun to identify the neuronal circuitry underlying the procognitive effects of selective nAChR agonists.

The empirical and conceptual complexities associated with the use of traditional cholinergic drugs as research tools generalize to efforts aimed at modeling and treating the cognitive symptoms of neuropsychiatric and neurodegenerative disorders. In particular, the role of abnormalities in cholinergic neurotransmission and eventually of cholinergic cell loss in the cognitive decline of Alzheimer's disease has been intensely debated, in part because the administration of $\mathrm{mAChR}$ antagonists to healthy subjects does not fully reproduce the symptoms of dementia (Flicker et al, 1992; Huff et al, 1988; Beatty et al, 1986; Kopelman and Corn, 1988; Fibiger, 1991). However, given the complex neuronal effects of mAChR antagonists described above, and specifically the increases in ACh release and subsequent nAChR stimulation, it should be expected that such drugs do not produce the range of cognitive impairments that results from the disintegration of cortical afferent, local, and efferent circuitry. Moreover, psychopharmacological studies aimed at modeling dementia have focused on the effects of acute administration of scopolamine or atropine (Beatty et al, 1986; Broks et al, 1988), or of a combination of $\mathrm{mAChR}$ and nAChR antagonists (Little et al, 1998). Therefore, debates about the limitations of such pharmacological models need to consider that effects of a single administration of a mAChR antagonist are contrasted against the chronic, escalating cognitive consequences of dysregulated and disintegrating cholinergic systems. In addition, the 
dementia of Alzheimer's disease is associated with neuronal death that destroys the input to and output from the hippocampal formation (Hyman et al, 1984), removing the glutamatergic circuits modulated by acetylcholine. In light of these considerations, the degree to which acute mAChR blockade models such dementias seems rather impressive (see also Christensen et al, 1992; Aarsland et al, 1994; Broks et al, 1988). The augmented cognitive impairment caused by scopolamine in healthy aged subjects (eg, Molchan et al, 1992; Sunderland et al, 1987, 1988), and the finding that scopolamine administration exacerbates the cognitive impairments of patients with Alzheimer's disease, further support the validity of this pharmacological model.

The limited therapeutic, procognitive efficacy of AChE inhibitors (eg, Pepeu and Giovannini, 2009) seems to be an expected finding when considering that inhibition of AChE is not capable of restoring or augmenting the phasic glutamatergic-cholinergic interactions that, as will be described below, mediate defined cognitive operations (see also Sarter and Bruno, 2002; Sarter et al, 2007). As noted above, the limited cognitive effects of acute mAChR antagonist administration does not reject the significance of this model for understanding the role of cholinergic cell loss in dementia (see also Bartus, 2000). Similarly, the finding that $\mathrm{AChE}$ inhibitors do not consistently produce robust beneficial cognitive enhancement does not serve as a conclusive basis for rejecting the hypothesis that a declining and dysregulated cholinergic system contributes to the severity of the symptoms of dementia (Mesulam, 2004). Moreover, a relatively small number of studies reported that $\mathrm{AChE}$ inhibitors produce small yet significant enhancement of cognitive, specifically attentional functions in patients with Alzheimer's disease (eg, Sahakian et al, 1993; Foldi et al, 2005). These complexities and resulting debates reflect the limited degree to which these drugs serve as sufficiently selective neuropsychopharmacological research tools, including for assessing the therapeutic potential of cholinergic treatment approaches.

\section{ACETYLCHOLINE AND THE REGULATION OF ATTENTION}

\section{Lesions and Early Microdialysis Studies}

A considerable amount of evidence from experiments on the effects of, initially, nonselective lesions of the basal forebrain (Robbins et al, 1989; Dunnett et al, 1991; Muir et al, 1992; Roberts et al, 1992; Voytko et al, 1994) and, subsequently, selective lesions of the basal forebrain cholinergic projections to the cortex (eg, McGaughy et al, 1996, 2000; Turchi and Sarter, 1997; McGaughy and Sarter, 1998; Chiba et al, 1995; Baxter et al, 1999; Dalley et al, 2004; Newman and McGaughy, 2008) indicated that these projections are necessary for performing tasks assessing a range of attentional functions.

The robustness and the selectivity of the attentional impairments produced by selective removal of cortical cholinergic inputs are noteworthy, particularly in light of a considerable literature reporting the absence of effects of such lesions on behaviors that require little or no attentional processing. For example, the effects of cholinergic lesions were assessed in animals performing a sustained attention task (SAT). The SAT consists of a random order of cued and blank trials. Responses are either hit or miss, or correct rejection and false alarm, respectively. Reward is delivered for both types of correct responses (hit or correct rejection; recorded through different levers). Incorrect responses (miss or false alarm) trigger the intertrial interval but do not have other scheduled consequences. Although intact animals detected over $70-80 \%$ of the longest ( $500 \mathrm{~ms}$ ) cues, cortical cholinergic deafferentation reduced the detection rate for all cues to approximately $30 \%$, with no recovery despite several months of daily postsurgery practice (McGaughy et al, 1996). At the same time, this deafferentation did not affect the animals' response accuracy in blank trials (ie, the correct reporting of the absence of a cue).

Another example illustrating the crucial significance of the cholinergic system for attention concerns the ability to divide attention between the processing of visual and auditory conditioned stimulus (Turchi and Sarter, 1997). Cortical cholinergic deafferentation did not affect the animals' performance in blocks of unimodal trials in which all cues were either visual or auditory. In contrast, under the condition of modality uncertainty, the lesion caused a profound speed-accuracy tradeoff, with correct responses requiring $700 \mathrm{~ms}$ longer in bimodal than in unimodal blocks of trials (for additional evidence illustrating disruption of basic attentional abilities by selective cholinergic lesions see, eg, Newman and McGaughy, 2008; Botly and De Rosa, 2009). The robustness and the selectivity of the cognitive impairments produced by such lesions is further supported, although indirectly, by a substantial number of experiments that concluded that removal of forebrain cholinergic neurons does not have strong effects on the performance of animals in tasks that do not explicitly tax attentional processes (Vuckovich et al, 2004; Frick et al, 2004). For example, cholinergic lesions of the medial septum cause only a mild impairment at all delays in a matching-to-place task in the Morris water maze (Baxter et al, 1995), and cholinergic lesions of the entire basal forebrain cause only a mild impairment in learning this task (Frick et al, 2004). Cholinergic lesions cause transient effects or no impairments in the radial arm maze (Chappell et al, 1998; Galani et al, 2002; Vuckovich et al, 2004) and T-maze alternation (Pang and Nocera, 1999; Galani et al, 2002). Cholinergic lesions of inferotemporal cortex in monkeys do not impair visual scene learning unless combined with fornix lesions (Browning et al, 2010).

Measures of ACh release in task-performing animals, using microdialysis, consistently showed attentional performance-associated increases in cortical ACh release. These increases in ACh release were not observed in animals performing behavioral procedures that controlled 
for noncognitive performance variables, such as lever pressing and reward rates, or the presentation of stimuli and distractors in contexts that do not require attention (eg, Himmelheber et al, 1997; Arnold et al, 2002). The results from more recent microdialysis studies indicated that levels of ACh release in attentional task-performing animals vary as a function of the demands on attention (or 'attentional effort') but do not correlate with levels of attentional performance (Passetti et al, 2000; Dalley et al, 2001; Kozak et al, 2006, 2007; Sarter et al, 2006).

\section{Cholinergic Mediation of Cue Detection}

As described above, the evidence from the experiments on the effects of cortical cholinergic deafferentation on SAT performance indicated a remarkably specific and robust impairment in performance (McGaughy et al, 1996; McGaughy and Sarter, 1998). Removal of cortical cholinergic inputs selectively and persistently impaired the animals' detection rate (or number of hits). In contrast, response accuracy in blank trials remained completely spared. This evidence indicates that the cholinergic system is required specifically for the detection of cues. In this context, detection is defined as a cognitive process that involves the insertion of a cue into ongoing behavioral and cognitive activity and subsequent control of such behavior by the cue (Posner et al, 1980).

The hypothesis deduced from these lesion experiments predicts that the cholinergic system is active specifically during trials involving cue detection. The use of enzymecoated microelectrodes for the amperometric measurement allows monitoring $\mathrm{ACh}$ release at a sub-second resolution and thus permits the demonstration of changes in $\mathrm{ACh}$ release in association with specific task events or behavioral responses (for evidence indicating the validity of this method see Burmeister et al, 2000; Parikh et al, 2004; Giuliano et al, 2008). The first experiments using this technique in task-performing animals used a

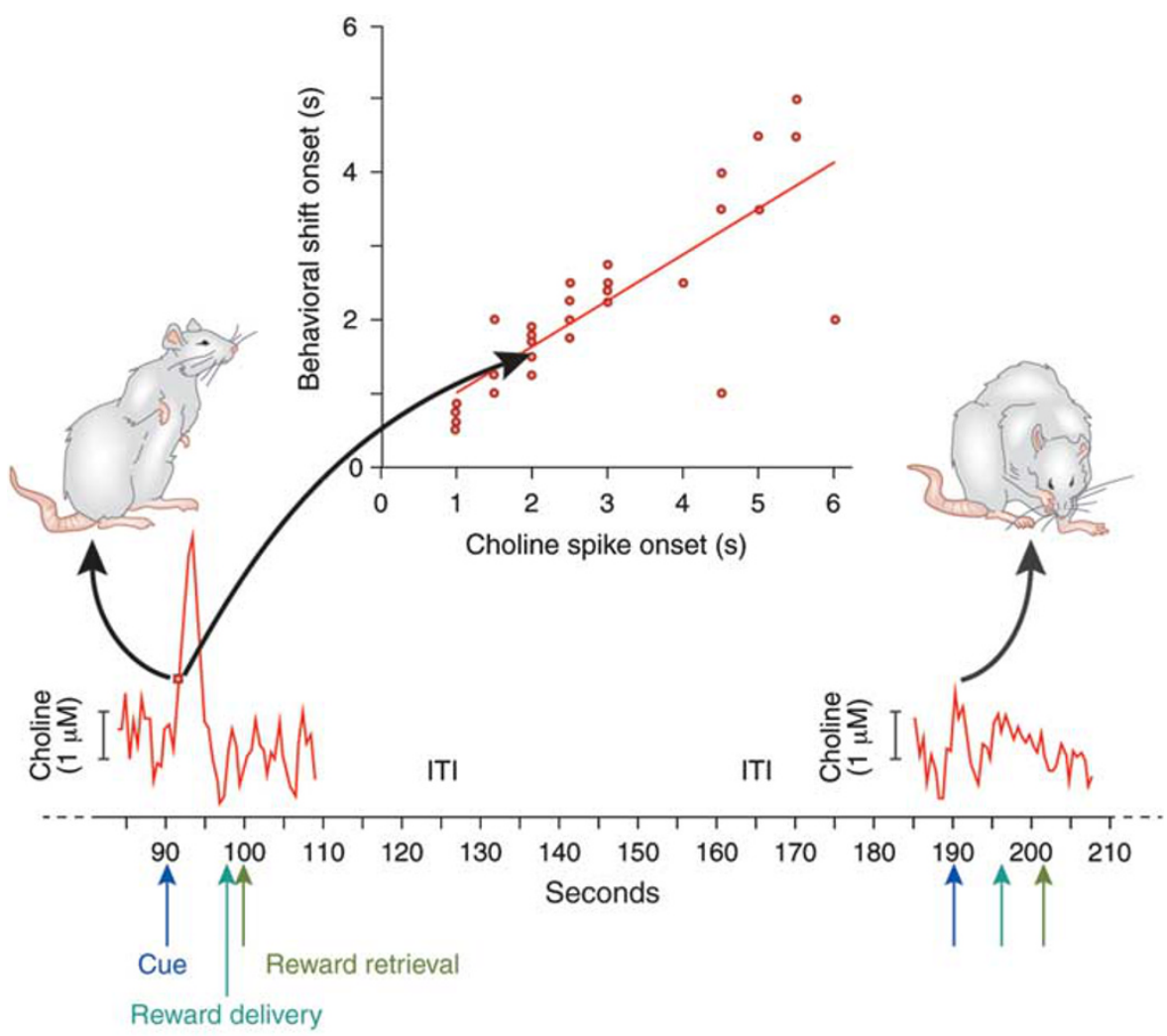

Figure 1. Prefrontal cholinergic transients mediating the detection of cues (data and components of this figure were adopted from Parikh et al, 2007). The abscissa depicts the time (seconds) over two trials, one in which the cue was detected (left) and one in which the cue was missed (right). Animals performed a cued appetitive response task. A light cue (presented for $1 \mathrm{~s}$; blue arrows) predicted reward delivery $6 \pm 2 \mathrm{~s}$ later at one out of two reward ports (dark green arrows). Detection was defined behaviorally by cue-evoked orientation toward and monitoring of the reward ports (as illustrated on the left). Animals detected most of the cues but occasionally missed cues (for detailed results see Parikh et al, 2007). Importantly, reward was also delivered if cues were missed, and animals retrieved the reward in such trials, although with longer response latencies. The intertrial interval (ITI) was $90 \pm 30 \mathrm{~s}$. The red traces depict electrochemical recordings of choline that were self-referenced against recordings from adjacent platinum recording site that lacked immobilized choline oxidase. As illustrated on the left, cues that were detected were associated with a cholinergic transient. The onset of the increase in cholinergic activity and the onset of detection-indicating behavior (defined in Parikh et al, 2007) were highly correlated (inserted plot; red dots and arrows indicating the timepoints for both measures). The initial, steep increase in cholinergic activity (between approximately 92 and $93 \mathrm{~s}$ on the abscissa) is thought to stimulate mAChRs, thereby initiating a period of persistent spiking (see Figure 3). During trials in which the cue was missed, no such transients were observed, and reward delivery and retrieval did not evoke increases in cholinergic activity (for details see Parikh et al, 2007). 
cued appetitive response task to determine cholinergic activity in the medial prefrontal cortex (mPFC) and a control region (forelimb region in the motor cortex). In this task (for details see Parikh et al, 2007), animals were presented with a rarely occurring cue that predicted subsequent reward delivery at one out of two reward ports. Animals detected the majority of these cues, as indicated by cue-evoked disengagement from ongoing behavior (usually grooming), and orientation toward, and monitoring of, the reward ports (see Figure 1). Occasionally, cues did not evoke such behavior. Video tape-based inspection of the animals' behavior during trials involving such misses indicated a brief, cue-evoked orientation-like response that, however, was followed by an immediate return to grooming behavior.

In the mPFC, cues that were detected evoked transient increases in cholinergic activity (Figure 1). Such transients were not observed in trials in which cues were missed, and they were not observed in motor cortex. Even if a cue was missed, reward was eventually delivered and retrieved. Recordings from such trials as well as from several control procedures indicated that the presence or absence of reward and reward-related behavior did not contribute to the generation of cholinergic transients. Furthermore, the timing of the peak amplitude varied with the duration of the interval between cue and reward, with peak times at approximately $1.5 \mathrm{~s}$ after cue presentation recorded in animals trained on shortest cue-reward intervals $(2 \pm 1 \mathrm{~s}$; see Parikh et al, 2007).

Collectively, the results from these experiments support the hypothesis that prefrontal cholinergic transients mediate cue detection (as defined above). Such transients were not observed in motor cortex. Removal of cholinergic input to the PFC impaired the animals' detection rate. Furthermore, because the attentional impairments caused by cholinergic lesions are not restored by pharmacologically mimicking the contributions of the tonic component of cholinergic neurotransmission (see below; McGaughy et al, 1999), the consequences of the lesions can be primarily attributed to the absence of cholinergic transients.

\section{Cholinergic Mode Switch, Orienting, and Detection}

On the basis of the findings described above, we predicted that in rats performing the SAT, cue-evoked cholinergic transients would occur in all trials in which cues are detected, but not in trials in which such cues are missed or during blank trials. Evidence from ongoing experiments (preliminary data were described in Howe et al, 2007) has challenged this hypothesis. As expected, cue-evoked cholinergic transients were observed in trials yielding hits. However, this was not consistently the case. Cholinergic transients were not observed in trials resulting in a hit if these trials were preceded by identical trials, that is, by cued trials ending with a hit. In contrast, transients were observed in cued trials resulting in a hit if preceded by a miss, or if preceded by 'blank' trials resulting in correct rejections.

Nonsignal trials do not involve the detection of cues and, thus, the performance in such trials is governed primarily by an extensively practiced response (a correct rejection); a response that is generated in the absence of a cue may constitute the default response (eg, Maclean et al, 2009). Cued trials resulting in misses can be categorized as perceived blanks and thus also be interpreted as reflecting the execution of a default response. In contrast, a hit requires that an external sensory cue is selected and incorporated into ongoing cognitive processing. Thus, it may be speculated that a cue may evoke a switch away from the default response mode, to a mode that increases the likelihood that it will be selected for behavioral and cognitive control (ie, detection; see above).

The nature of this mode switch may conceptually correspond with Posner's concept of attentional 'orienting', defined as a mental process designed to align attention with a source of sensory input. Importantly, Posner clearly differentiates between orienting and the cognitive act of cue detection, emphasizing that '... some responses (eg, saccadic eye movements) may be available to a stimulus before it has been detected...' (Posner, 1980; p 4). Attentional orienting, overtly or covertly, fosters cue detection; however, orienting is neither sufficient nor necessary for detection. The conceptualization of cholinergic transients in terms of mediating attentional orienting is consistent with the finding that cholinergic lesions or systemic or local cortical blockade of mAChRs impair attentional orienting (Davidson and Marrocco, 2000; Davidson et al, 1999; Chiba et al, 1999; Phillips et al, 2000). As orienting is not necessary for detection, the residual hit rate after cortical cholinergic deafferentation (McGaughy et al, 1996) may have been because of detections that occurred without the facilitating benefits of attentional orienting.

In keeping with this conceptualization, misses are attributed to orienting failures, therefore decreasing the likelihood for subsequent detection and increasing the likelihood that the default response (a correct rejection) will be executed (and counted as a miss in a cued trial). The model described below, specifically the key interactions between thalamic glutamatergic and cholinergic afferents of the PFC, is capable of explaining why less salient cues are more likely to fail in generating cholinergically mediated attentional orienting and thus are more likely to be missed.

This conceptualization further requires the assumption that after a hit, attention was successfully aligned with the source of input and that this alignment remains stable for a brief period of time (perhaps 10-20 s during SAT performance; ITI: average of $9 \mathrm{~s}$ ). If the subsequent trial is cued, detection of this cue therefore would not require attentional (re-) orienting, and therefore, transients are not observed in successive trials ending with hits. Further below we will speculate about neuronal mechanisms mediating the transfer of cue-evoked attentional orienting to the next 
trial. If the next trial is a noncued trial, the circuit returns to the default state and a subsequent cue is again more likely to be detected if it evokes attentional orienting. Whether SAT performance permits identifying a behavioral correlate of orienting that can be dissociated from the obvious behavior that indicates detection (a hit) is currently being explored.

Orienting differs from 'alerting', which is defined as 'achieving and maintaining a state of high sensitivity to incoming stimuli' (Posner and Rothbart, 2007; p 7), and presumably varies on a longer timescale (minutes and tens of minutes) than orienting (milliseconds and seconds). Although other neuromodulator systems, specifically the noradrenergic system (eg, Witte and Marrocco, 1997; Posner, 2008), have been proposed to contribute to alerting, in the context of a circuitry model (below), we will suggest that a tonic component of cholinergic neurotransmission may also contribute to alerting and thereby to successful orienting, perhaps in part through local cortical and distributed interactions between the two neuromodulator systems (Briand et al, 2007; Dalley et al, 2001).

\section{Neurophysiological Correlates of Mode Shifts}

Previous neurophysiological research, recording from brain slices, concluded that ACh acts to enhance the (glutamatergic) representation of thalamic input through stimulation of nAChRs, while suppressing cortico-cortical or associational input through stimulation of mAChRs (Hasselmo and Bower, 1992; Hasselmo et al, 1992; Hasselmo and Schnell, 1994; Gil et al, 1997; Kimura and Baughman, 1997; Roberts et al, 2005; see below). The cholinergically mediated shift from a default mode to the detection mode, or orienting (above), corresponds conceptually with the conclusions from this neurophysiological work. Orienting is generated in part by enhancing the cortical representation of thalamic input. At the same time, the cortico-cortical (associational or default mode-based) processing would need to be suppressed to minimize interference with effective orienting and the subsequent detection process. Through stimulation of mAChR, we may also begin to speculate about mechanisms that sustain orienting over longer periods of time, allowing successive detections to occur without generating additional cholinergic transients (see below).

\section{PREFRONTAL CIRCUITRY MEDIATING ORIENTING AND DETECTION: TOWARD A MECHANISTIC MODEL OF CHOLINERGIC FUNCTION}

Evidence from neuropharmacological studies, including from animals lacking various nAChRs after lesions of the thalamic mediodorsal (MD) nucleus projections to PFC or after removal of mesolimbic dopaminergic projections to the PFC, has begun to define key components of a circuit that mediates orienting and thereby fosters cue detection (Parikh et al, 2008; Parikh et al, 2010; Sarter et al, 2009b).
Importantly, some essential features of this circuitry have been validated in terms of predicting the effects of cholinergic drugs on attentional performance (Howe et al, 2010). This section will focus on this model and therefore will combine evidence from electrochemical and behavioral studies with hypotheses and, to a minor degree, some speculations.

Before addressing details in support of this circuitry model, and as illustrated in Figure 2, it is useful to introduce an important yet potentially complicating aspect of this model. The model postulates that cholinergic projections to the PFC have two separate roles. First, evidence indicates that, by stimulating a specific $\mathrm{nAChR}$ subtype expressed by inputs from the $\mathrm{MD}$, cholinergic activity modulates glutamatergic neurotransmission. Second, as was also shown, such glutamate release dictates, through stimulation of ionotropic glutamate receptors, the amplitudes of the cholinergic transients that mediate, as is hypothesized above, attentional orienting and foster cue detection. The model speculates that separate populations of cholinergic neurons influence the release of glutamate from MD inputs and are targeted by such inputs, respectively (Figure 2). Although evidence supporting such a segregation of cholinergic projections has remained limited, our current model is consistent with contemporary anatomical theories suggesting a highly differentiated, topographic organization of the cholinergic system (Zaborszky, 2002; Zaborszky et al, 2005, 2008).

\section{Prefrontal Glutamatergic-Cholinergic Interactions}

Evidence from neuropharmacological studies using selective $\mathrm{nAChR}$ ligands and antagonists at ionotropic glutamate receptors, and assessing the effects of infusions of these compounds into the PFC of animals lacking $\alpha 4 \beta 2^{*}$ or $\alpha 7$ nAChRs, or animals with lesions of the MD, collectively indicated that the amplitude of cholinergic transients is determined by glutamatergic stimulation of ionotropic glutamate receptors. Furthermore, cholinergic stimulation of $\alpha 4 \beta 2^{*} \mathrm{nAChRs}$ evoked cholinergic transients through stimulating glutamate release, and the MD input is required to generate such transients. In contrast to the amplitude of cholinergic transients, the decay rate of such transients, that is, the duration and rate of decrease of ACh release, is not controlled by these glutamatergic-cholinergic interactions (Parikh et al, 2008, 2010; Howe et al, 2010).

We can only speculate about the nature of the information about the cue that is 'imported' by MD projections. The MD may be considered as the thalamic 'exit' station for a circuit that involves projections from sensory cortical regions to the thalamic reticular nucleus that, in turn, projects to the MD. This circuit has been proposed to generate preattentionally processed representations of cues (Guillery et al, 1998; Zikopoulos and Barbas, 2006, 2007a, b; Pinault, 2004; Weese et al, 1999; McAlonan et al, 2006). The term 'pre-attention' has often been explained using the 
PFC

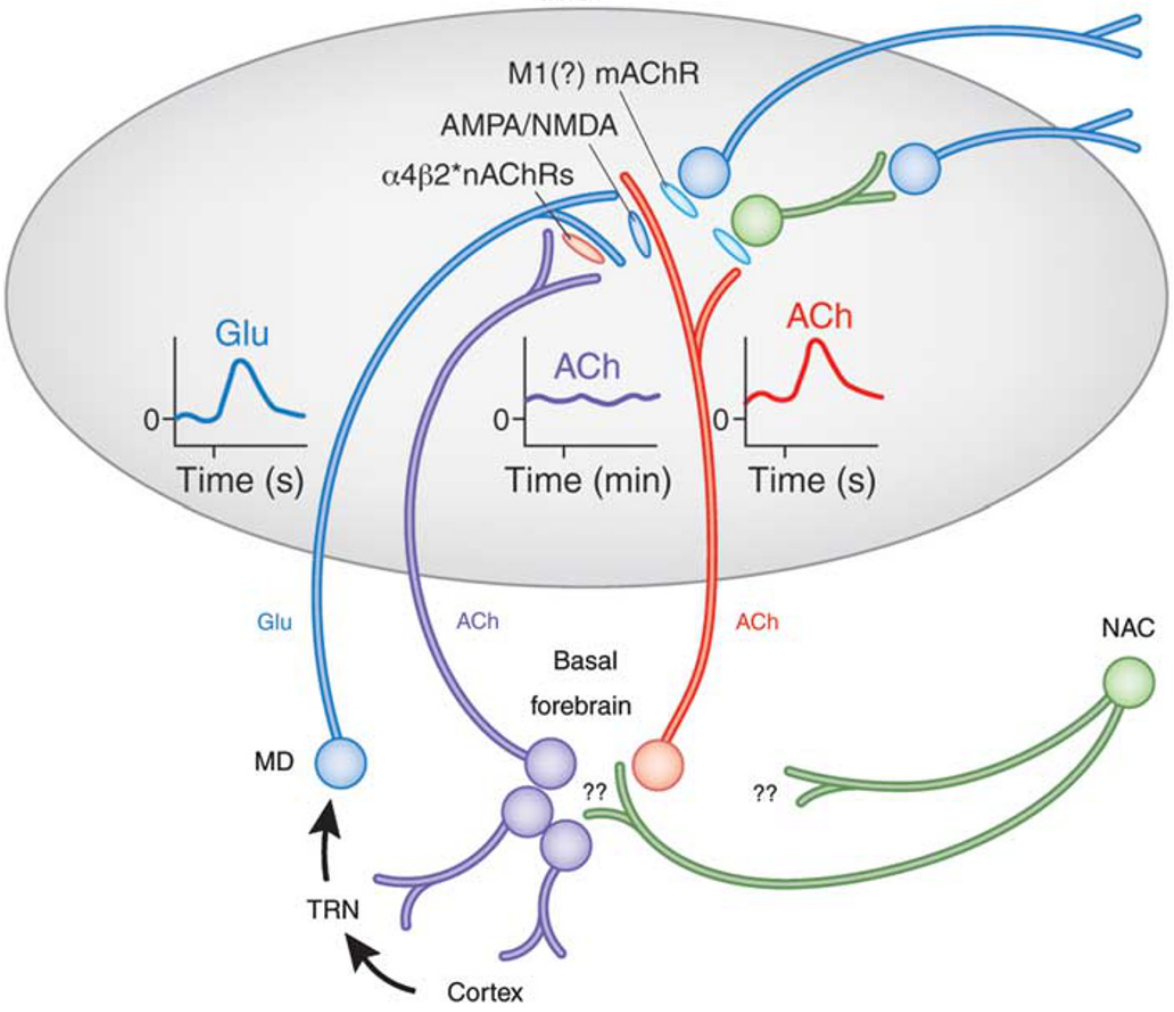

Figure 2. Circuitry model describing the main components of the prefrontal cortex (PFC) circuitry mediating signal detection and processing mode shifts. The model combines evidence with parsimonious assumptions required to explain electrochemical and attentional performance data (see main text for details). The glutamatergic (GLU) inputs to the PFC, originating from the mediodorsal thalamic nucleus (MD) 'import' a preattentionally processed representation of the signal into the PFC (see text for definition). MD neurons are part of a network that includes the thalamic reticular nucleus (TRN) and its topographic afferents from sensory cortical regions. The cue-evoked glutamatergic transient (see insert) generates a cholinergic transient (see insert) through stimulation of ionotropic presynaptic glutamate receptors (Parikh et al, 2008, 2010). This cholinergic transient mediates the actual detection process or, depending on the task, a processing mode shift that fosters detection (see main text). Prefrontal output neuron activity is stimulated by ACh primarily through muscarinic $(\mathrm{m}) \mathrm{AChRs}$, thereby organizing the behavioral responses that indicate successful detection. The terminals of the MD inputs to the PFC are equipped with $\alpha 4 \beta 2^{*}$ nAChRs. Cholinergic stimulation of these receptors is thought to vary over minutes, reflecting a tonic component of cholinergic neurotransmission (see elevated release illustrated by the insert). nAChR agonists enhance detection performance primarily by positively modulating GLU release from these terminals, thereby augmenting the amplitudes of the cholinergic transients (Parikh et al, 2010; Howe et al, 2010). As is further explained in the text, this model therefore proposes two separate roles for cholinergic inputs, mediated through separate populations of cholinergic neurons. A rather tonically active input modulates glutamate release from MD neurons that, in turn, target the terminals of a separate group of cholinergic neurons, generating the transients that enhance attentional orienting and cue detection (adapted and modified from Sarter et al, 2009b).

'attentional searchlight' analogy, '...like a searchlight at dusk, it intensifies part of a scene that is already visible to some extent' (Crick, 1984; p 4586). Such a preattentional narrowing may be considered a necessary precursor of attentional orienting (as defined above), as the former concerns attention to part of a scene (eg, attention toward an intelligence panel of an operant chamber) whereas the latter concerns the orientation of attention to a specific source for a target (eg, attention to the location of a bulb). Attentional orienting may also involve prospective timing processes and estimating target onset.

Exactly how MD projections to the PFC encode the searchlight effect and bias the processing of information by PFC circuitry toward a particular part of a scene is not understood. Similarly, exactly how PFC cholinergic transients further narrow and presumably specify such biasing or, to keep with the searchlight analogy, increase the brightness and the focus of the searchlight to illuminate a specific aspect of the scene remain speculative. Certainly, these processes involve top-down control, as the scene and the target that are subject to preattentional processes and attentional orienting are guided by their established significance. It is noteworthy, however, that preattentionprocessing thalamic nuclei, including the $\mathrm{MD}$, also receive cholinergic input from the basal forebrain (eg, Hallanger et al, 1987; see Figure 2), suggesting an orchestrated cholinergic recruitment of thalamic and cortical circuitries to foster cue detection.

These glutamatergic-cholinergic interactions do not readily account for occasional misses of salient stimuli. We hypothesize that as a result of, for example, taskunrelated increases in activity in this network before the presentation of signals, as shown in Parikh et al (2007), attentional interference results from GABAergic inhibition 
of the cholinergic terminals that generate transients (Rasmusson et al, 2007). The cholinergic receptors situated on GABAergic interneurons are not clear but likely involve ${ }^{*} \beta 2^{*}$ subunit containing nAChRs and also mAChRs (Bandyopadhyay et al, 2006; Azam et al, 2003; Disney and Aoki, 2008).

\section{Prefrontal nAChR-Mediated Upregulation of Glutamatergic-Cholinergic Interactions}

The glutamatergic terminals of $\mathrm{MD}$ projections express $\alpha 4 \beta 2 *$ nAChRs (Lambe et al, 2003: Figure 2). We showed that removal of these thalamic inputs blocks the ability of $\alpha 4 \beta 2^{*} \mathrm{nAChR}$ agonists to evoke glutamatergic and cholinergic transients (Parikh et al, 2010). Furthermore, stimulation of $\alpha 4 \beta 2^{*}$ nAChRs, by administering systemically a full $\alpha 4 \beta 2^{*} \mathrm{nAChR}$ agonist, increased the number of cue detections in SAT-performing animals; this effect was observed specifically during performance recovery subsequently to the presentation of a distractor ('dSAT' performance; Howe et al, 2010). Moreover, this increase in hits occurred specifically in trials that were preceded by misses or blanks, consistent with the hypothesis that $\alpha 4 \beta 2^{*}$ nAChR agonists facilitate the generation of cholinergic transients that foster attentional orienting and/or the shift into the detection mode. As already mentioned, removal of cholinergic neurons abolishes this effect of stimulation of $\alpha 4 \beta 2^{*}$ nAChRs.

The effects of $\alpha 4 \beta 2^{*} \mathrm{nAChR}$ agonists are thought to mimic the effects of a more tonic component of cholinergic neurotransmission at these receptors. In addition to the second-based cholinergic transients, several sets of data suggest that more slowly changing (tonic; scale of minutes and tens of minutes) levels of cholinergic neurotransmission are also present in this system. First, in our previous microdialysis studies we observed increases in cholinergic neurotransmission before the onset of the attention task (Kozak et al, 2006, 2007). These increases were interpreted as evoked by the testing context and anticipation of performance and associated reward. Ongoing studies suggest that these tonic changes in cholinergic activity are not confounded by phasic cholinergic activity. Rather, the direction of changes in tonic cholinergic activity (as indicated by microdialysis) and the amplitudes of cholinergic transients (measured electrochemically) are not necessarily correlated and, as evidenced by effects of different $\mathrm{nAChR}$ agonists on both measures, may in fact be dissociated ( $G$ Paolone, unpublished findings; see also Parikh and Sarter, 2008).

The model illustrated in Figure 2 implies that a separate group of cholinergic neurons contacts $\mathrm{MD}$ glutamatergic terminals in the PFC, allowing for relatively slowly changing levels of ACh released by these neurons to modulate the gain of glutamatergic-cholinergic interactions through stimulation of $\alpha 4 \beta 2^{*} \mathrm{nAChRs}$. Evidence indicating that $\alpha 4 \beta 2^{*}$ nAChRs do not downregulate in response to lasting cholinergic stimulation (Walsh et al, 2008; Yates et al, 1995) is consistent with this assumption. As a result, the likelihood and the amplitude of cholinergic transients are increased over longer periods of time (minutes to hours).

The effects of such tonic cholinergic modulation of the efficacy of cortical information processing conceptually may correspond with the more traditional view of the role of cholinergic inputs in elevating levels of 'arousal', 'the readiness for input processing', or to enhance preattentional processes (for corresponding conclusions about the role of nAChRs in the thalamic input layer of V1, see Disney et al, 2007). Furthermore, the effects of motivational variations of cognitive performance, specifically the mesolimbic-basal forebrain interactions that control levels of attentional effort (Zmarowski et al, 2005, 2007; Sarter et al, 2006), are readily integrated into this model. Mesolimbic systems selectively and tonically influence cholinergic neurotransmission of prefrontal inputs and thereby gate prefrontal glutamatergic-cholinergic interactions as a function of the motivation to perform, particularly in interaction with performance challenges (Kozak et al, 2006).

\section{ROLE OF CHOLINERGIC RECEPTORS IN ATTENTION}

\section{Nicotinic AChRs}

$\alpha 4 \beta 2^{*} n A C h R s$. A substantial number of studies showed that administration of nicotine enhances attentional performance and aspects of memory encoding (eg, Wesnes and Warburton, 1984; Rusted and Warburton, 1992; Levin et al, 1998). However, the demonstration of large and clinically useful effects of nicotine has been difficult (for review, see Rusted et al, 2000; Newhouse et al, 2001, 2004; Sarter et al, 2009b; Sarter, 2010). Recent studies have indicated that agonists selective for $\alpha 4 \beta 2^{*} \mathrm{nAChRs}$ produce perhaps more robust and clinically more promising enhancement of attention and related cognitive abilities (Potter et al, 1999; Wilens et al, 1999; Wilens et al, 2006; Dunbar et al, 2007; Wilens and Decker, 2007).

Evidence from animal studies on the effects of a full agonist at $\alpha 4 \beta 2^{*} \mathrm{nAChRs,} S$ 38232, confirmed that such compounds are more efficacious in enhancing attentional performance than nicotine (Howe et al, 2010). We explored the hypothesis, deduced from studies on prefrontal circuitry involved in the effects of stimulation of nAChRs (Parikh et al, 2008; Parikh et al, 2010), that stimulation of the $\alpha 7 \mathrm{nAChR}$ limits the proattentional efficacy of nicotine. Indeed, although the administration of nicotine alone did not statistically improve performance, coadministration of nicotine and the $\alpha 7 \mathrm{nAChR}$ antagonist methyllycaconitine (MLA) resulted in a significant enhancement of attention. Corresponding with the behavioral evidence, this combination treatment also 'sharpened' the cholinergic transients evoked by nicotine (Howe et al, 2010), suggesting that the more lasting increases in cholinergic activity that result from stimulation of the $\alpha 7 \mathrm{nAChR}$ limits the efficacy of nicotine. With respect to the model illustrated in Figure 2, 
the beneficial cognitive effects of $\alpha 4 \beta 2^{*} \mathrm{nAChR}$ agonists are hypothesized to manifest as an upregulation of transient, glutamatergic-cholinergic interactions.

$\alpha 7 n A C h R s$. There is currently a substantial enthusiasm for the potential procognitive therapeutic efficacy of $\alpha 7 \mathrm{nAChR}$ agonists (Leiser et al, 2009; Freedman et al, 2008). The $\alpha 7$ nAChR has a relatively high permeability for $\mathrm{Ca}^{++}$and thereby induces vesicular fusion and neurotransmitter release from presynaptic terminals and activates calciumsensitive protein kinases postsynaptically (Gray et al, 1996; Berg and Conroy, 2002; Bitner et al, 2007). Such mechanisms could account for lasting and diverse effects at target neurons and presynaptic terminals, including cholinergic terminals (Duffy et al, 2009).

The evidence indicating beneficial attentional effects of $\alpha 7 \mathrm{nAChR}$ agonists remains conflicting. Pharmacological studies failed to implicate this receptor in attention (Grottick and Higgins, 2000; Hahn et al, 2003). Similarly, we were not able to observe beneficial attention effects of the administration of the $\alpha 7 \mathrm{nAChR}$ agonist ABT 107 on either basic SAT performance or on the recovery from the distractor challenge (Paolone et al, 2009). In contrast, attentional impairments were observed in mice lacking the $\alpha 7$ nAChR (Hoyle et al, 2006; Young et al, 2007).

As mentioned above, evidence indicates that, in the presence of an antagonist at the $\alpha 7 \mathrm{nAChR}$, nicotine enhanced attentional performance. The electrochemical effects of this combination indicated that stimulation of the $\alpha 7 \mathrm{nAChR}$ was responsible for the relatively slow rise time and decay rate of nicotine-evoked cholinergic transients. Compared with the 'sharper' transients evoked by $\alpha 4 \beta 2^{*} \mathrm{nAChR}$ agonists and observed in task-performing animals, the more enduring ACh release evoked by nicotine, primarily through stimulation of the $\alpha 7 \mathrm{nAChR}$, is hypothesized to interfere, or at least limit, the more precise amplification of glutamatergic-cholinergic interactions that enhance cue detection performance.

Given the diverse neuronal effects triggered by $\alpha 7$ nAChR-mediated calcium influx, it is conceivable that agonists at this receptor alter and may even benefit a range of physiological, behavioral, and cognitive functions (eg, Bitner et al, 2007). However, the available evidence, although remaining limited, does not indicate that stimulation of this subtype benefits detection and associated attentional performance.

\section{Muscarinic AChRs}

Upon release, ACh also stimulates muscarinic receptors. A number of studies have shown the involvement of muscarinic receptors in the modulation of attention. As already discussed, the lack of selective antagonists and agonists at muscarinic receptor subtypes has remained a major obstacle for research on the functions of mAChRs. New M1-selective ligands have become recently available, including, importantly, a positive allosteric modulator (Sheffler et al, 2009; Shirey et al, 2009).

However, despite such limitations, a considerable literature describes robust scopolamine-induced attentional impairments in healthy subjects (see Introduction for a more general discussion of the effects of $\mathrm{mAChR}$ antagonists as a model for dementia). These studies uniformly indicate that blocking mAChRs disrupts continuous or sustained attention, the detection of cues in attentional contexts, and the resulting encoding of new information (eg, Dunne and Hartley, 1986; Parrott, 1986; Wesnes et al, 1988).

The effects of mAChR blockade in sensory and associational cortical regions parallel the consequences of systemic blockade in humans. Herrero et al (2008) showed that in the primary visual cortex, blockade of muscarinic but not nicotinic AChRs impaired the attentional modulation of V1 neurons (see also Deco and Thiele, 2009). Using a cued target detection task, Davidson and Marrocco (2000) found that blockade of $\mathrm{mAChR}$ in the intraparietal cortex impaired performance. Stimulation of $\mathrm{mAChRs}$ in parietal regions is speculated to contribute to the recruitment of local and efferent circuitry that enhance cue processing and distractor filtering (see effects of cholinergic deafferentation of the parietal cortex in Broussard et al, 2009).

Stimulation of mAChRs in one region may modulate attentional mechanisms in other regions by influencing ACh release through larger, multisynaptic mechanisms. For example, stimulation of PFC muscarinic receptors influences ACh release in parietal cortex, presumably through prefrontal projections to the basal forebrain and/or corticocortical networks (Nelson et al, 2005). Such prefrontal, muscarinic recruitment of efferent circuitry may mediate top-down effects to, for example, combat performance decay as a result of time-on-task and other performance challenges, such as distractors (Gill et al, 2000; Kozak et al, 2006; Sarter et al, 2006). Evidence indicating scopolamineinduced impairments in attentional set shifting performance (Chen et al, 2004) is consistent with a role of $\mathrm{mAChR}$ for the mediation of cognitive functions that involve top-down control.

The hypothesis that nAChRs mediate attentional orienting and cue detection whereas mAChRs recruit circuitry that is required for attentional performance in situations demanding top-down control suggests that both cholinergic receptor populations act synergistically to support performance (see also Greenwood et al, 2009). This basic hypothesis indicates the need for studies assessing the consequences of combined antagonisms of nicotinic and muscarinic AChRs. It will also be important to determine whether the location of mAChRs predominantly on GABAergic interneurons, showed in V1 (Disney and Aoki, 2008), generalizes to other cortical regions. Such a preferential distribution of nAChRs in thalamic input layers and mAChRs on cortical inhibitory interneurons would be consistent with hypotheses describing the complementary roles of ACh on cue detection on one hand, and interference filtering and cue competition resolution on the other 
(Mitchell et al, 2007). Furthermore, as will be addressed below, stimulation of mAChRs evoke persistent firing patterns that may serve to stabilize the state of attention circuits and maintain cue representation over longer periods of time.

\section{Evidence from Human fMRI Studies Assessing AChE Inhibitors}

As discussed in the Introduction, the interpretation of the effects of AChE inhibitors requires caution in view of the complex pre- and postsynaptic consequences of large increases in extracellular ACh levels. Despite these complexities, results from fMRI studies using physostigmine and, less frequently, donepezil indicate that these drugs have continued to serve as productive tools. These studies collectively indicated that $\mathrm{AChE}$ inhibition facilitated stimulus-induced increases in activity in several brain regions, depending in part on the type of task and the nature of the stimuli. As a result, memory-based performance was facilitated, and often associated, with reduced activity in prefrontal and even sensory regions. The latter finding has been interpreted as indicating the beneficial consequences of enhanced encoding for the performance during the memory test (eg, Furey et al, 2000; Robbins et al, 2000; Bentley et al, 2004, 2009; Kukolja et al, 2009). Furthermore, several studies identified enhanced attention to stimuli as a key mechanism that contributes to the effects of physostigmine on encoding, and determined that frontoparietal as well as sensory and sensory-associational areas mediate these effects (eg, Bentley et al, 2003, 2008; Furey et al, 2008; Silver et al, 2008). In broadest terms, these conclusions correspond with the role of increases in cortical cholinergic activity for attentional orienting and cue detection that has been derived from animal studies (above).

Although the behavioral or cognitive effects of AChE inhibitors in these fMRI studies were not consistently present or were of limited magnitude, the collective evidence from these studies has raised important questions as to the effects of AChE inhibitors on extracellular levels of ACh in task-performing subjects. Specifically, it would be of interest to determine the orchestration of cholinergic transients against a background of increased levels of synaptic and perhaps extrasynaptic ACh (Sarter et al, 2009a). Unfortunately, the electrochemical techniques for the rapid measurement of $\mathrm{ACh}$ release prohibit the presence of an AChE inhibitor as this would block the generation of the reporter molecule (choline). Thus, studies of AChE effects at a high temporal resolution will require future, alternative measurement techniques.

\section{fMRI Studies Assessing Nicotine or Scopolamine}

Similar to the purely behavioral studies discussed above, administration of nicotine to subjects undergoing fMRI scanning did not consistently produce significant effects on cognitive performance (Giessing et al, 2006; Thiel and Fink, 2008; Vossel et al, 2008). However, consistent with the conclusions derived from experiments in rodents, nicotine enhanced neuronal activity in prefrontal cingulate and parietal regions specifically in trials requiring cue detection and attentional re-orienting in subjects performing a cued target detection task (Giessing et al, 2006; Vossel et al, 2008). Additional analyses indicated that individual differences in performance-associated activity in prefrontal and parietal regions predict performance effects of nicotine (Giessing et al, 2007). Although we do not know the relationships between (transient) cholinergic activity and blood oxygenation level-dependent contrast or other hemodynamic responses, it is intriguing to speculate that a significant proportion of the nicotine-induced activation of specifically prefrontal regions is causally related to the drug-induced augmentation of cholinergic transients that mediate cue detection and attention mode shifts.

fMRI studies that investigated the effects of scopolamine have focused on memory performance and, to our knowledge, did not study attention. These studies must be interpreted with awareness of the effects of blocking preand postsynaptic muscarinic receptors (see Introduction) and potential effects of the blockade of ACh-induced vasodilation through M5 mAChR (Yamada et al, 2003). Studies on scopolamine have produced a range of performance effects on memory tasks and associated changes in blood flow occurring in a diverse set of brain regions (Grasby et al, 1995; Bozzali et al, 2006). Consistent with the general view that attention-dependent encoding depends on stimulation of mAChR in hippocampal, parahippocampal, and entorhinal regions, several studies showed disruption of encoding-evoked neuronal activity in these regions and resulting impairments in recognition memory (Rosier et al, 1999; Schon et al, 2005).

\section{CHOLINERGIC MODULATION OF CELLULAR PHYSIOLOGY}

Intracellular recordings of the cellular modulatory effects of ACh provide additional information about the functional role of ACh. Cellular data on the effects of ACh in cortical structures guide the development of circuit-level models of the behavioral role of ACh (Hasselmo, 2006; Hasselmo and Stern, 2006). The effects of ACh within cortical structures are consistent with a role of $\mathrm{ACh}$ in attentional orienting and cue detection (above). Previous studies have shown that stimulation of nAChRs enhances the glutamatergic transmission at thalamocortical synapses (Gil et al, 1997; Gioanni et al, 1999; Hsieh et al, 2000), thereby enhancing the thalamic activation of subsets of cortical neurons. The spiking response of cortical neurons to sensory input is further enhanced by muscarinic receptors causing a decrease in potassium conductances, including resting conductances (Krnjevic et al, 1971; Cole and Nicoll, 1984; Barkai and Hasselmo, 1994; Gulledge et al, 2009), the 
M current (Madison et al, 1987), and the calcium-dependent potassium current (Madison and Nicoll, 1984; Schwindt et al, 1988; Barkai and Hasselmo, 1994; Gulledge et al, 2009).

Muscarinic receptor activation also causes heterosynaptic and presynaptic inhibition of glutamatergic synaptic transmission at excitatory recurrent synapses between neurons within the cortex (Hasselmo and Bower, 1992; Hasselmo and Schnell, 1994; Hasselmo and Cekic, 1996; Kimura, 2000; Kimura and Baughman, 1997), thereby reducing the spread of neural activity and enhancing the relative influence of external input on cortical activity. These cellular effects are consistent with unit recording and fMRI data showing that cholinergic modulation reduces the spatial spread of activity in visual cortex (Roberts et al, 2005; Roberts and Thiele, 2008; Silver et al, 2008) and showing that cholinergic mechanisms underlie the enhancement of unit responses with attention (Herrero et al, 2008; Roberts and Thiele, 2008).

The relative influence of external input can also be enhanced by cholinergic depolarization of selective sets of inhibitory interneurons (Xiang et al, 1998; McQuiston and Madison, 1999a, b, c; Christophe et al, 2002), coupled with the cholinergic suppression of evoked GABAergic synaptic transmission (Pitler and Alger, 1992; Behrends and ten Bruggencate, 1993; Patil and Hasselmo, 1999). Computational modeling of cortical circuitry indicates that these effects of cholinergic modulation on inhibitory neurons can enhance the response to sensory input while reducing background activity in cortical circuits (Patil and Hasselmo, 1999). Cholinergic modulation also causes transient inhibition of layer $\mathrm{V}$ neocortical neurons, thereby reducing cortical output (Gulledge and Stuart, 2005).

In addition to the enhancement of attention to sensory input, other cellular effects of ACh could contribute to active maintenance of stimuli. ACh enhances persistent spiking or plateau potentials within cortical structures, as shown in brain slice preparations of the entorhinal cortex (Klink and Alonso, 1997; Egorov et al, 2002; Fransen et al, 2006; Tahvildari et al, 2007), PFC (Haj-Dahmane and Andrade, 1996, 1997, 1998), postsubiculum (Yoshida and Hasselmo, 2009), and perirhinal cortex (Leung et al, 2006). In the absence of cholinergic modulation, cortical neurons in slices will usually only spike during direct depolarizing current injection, terminating their spiking after the current injection ends. In contrast, in the presence of drugs that activate muscarinic acetylcholine receptors, a neuron responds to the same current injection with spiking that continues after the termination of the current injection (see Figure 3). The cholinergic enhancement of persistent spiking is reduced by muscarinic antagonists such as scopolamine, indicating a dependence on mechanisms activated by mAChRs (Klink and Alonso 1997; Egorov et al, 2002; Yoshida and Hasselmo, 2009). This persistent spiking occurs even when glutamatergic and GABAergic synaptic connections have been blocked pharmacologically, indicating that it arises from intrinsic mechanisms for

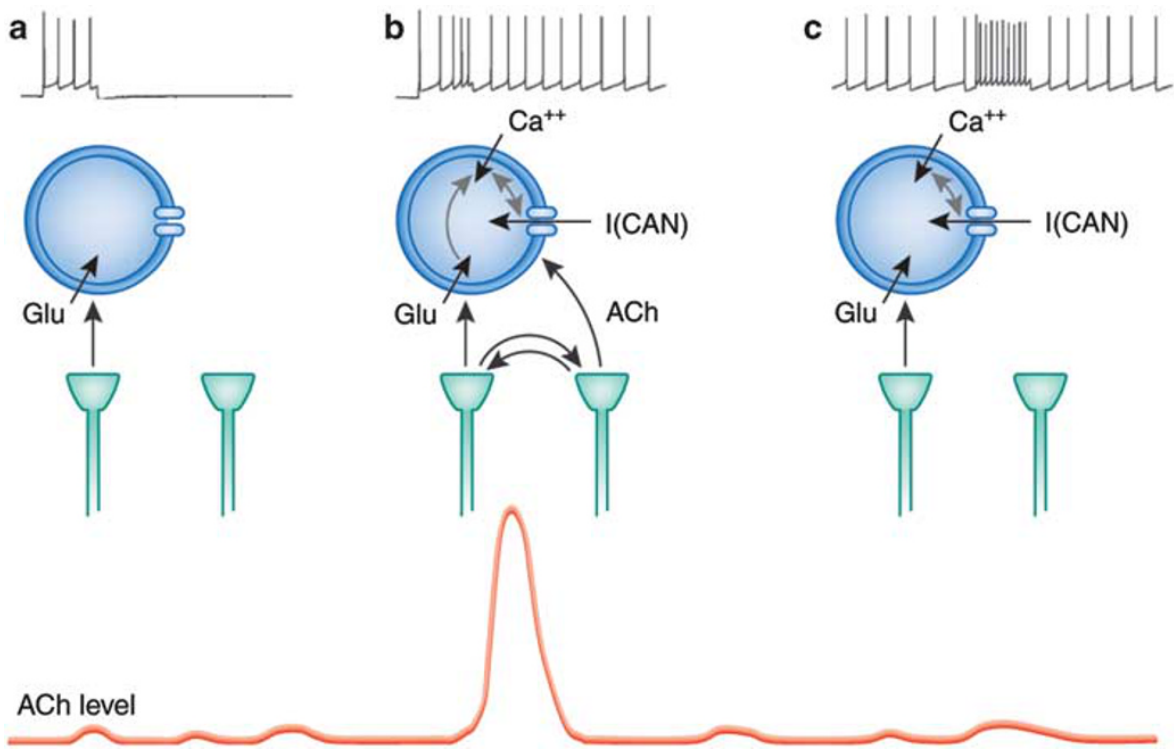

Figure 3. Theoretical perspective on the interaction of glutamatergic and cholinergic input for inducing persistent spiking in cortical structures. (a) Depolarization of cortical neurons because of glutamatergic input alone causes a transient period of spiking that ends after depolarization. (b) In an attentional task, a cue triggers glutamatergic input that causes a local positive feedback interaction with cholinergic terminals. This can cause a transient increase in acetylcholine (ACh) levels associated with cue detection (bottom) as also shown in Figure 1. Slice physiology studies (Egorov et al, 2002; Shalinsky et al, 2002; Yoshida and Hasselmo, 2009) have shown that an ACh increase combined with calcium influx (because of glutamatergic input) activates the calcium-sensitive nonspecific cation current I(CAN) current in the membrane that causes depolarization that causes further calcium influx that keeps the current activated. This results in self-sustained persistent spiking (Fransen et al, 2002; Fransen et al, 2006; Hasselmo and Stern, 2006) that provides active maintenance of network activity such as the plan for a future lever press response. (c) If persistent spiking has been induced by a previous cue, then the persistent spiking continues through the next trial and does not require cueing. The persistent activity might suppress the mechanism for transient increase in ACh levels, resulting in the lack of an cholinergic transient for a cue trial after a successful cue trial. 
self-sustained persistent spiking activity. Persistent spiking seems to result from muscarinic receptor activation of a calcium-sensitive nonspecific cation current I(CAN) (Egorov et al, 2002; Shalinsky et al, 2002; Fransen et al, 2006). As shown in Figure 3, during muscarinic receptor activation the spiking caused by glutamatergic synaptic input causes calcium influx through voltage-dependent calcium channels that increase the I(CAN) current, causing further depolarization and regenerative persistent spiking (Fransen et al, 2006; Hasselmo and Stern, 2006).

Cholinergic induction of persistent spiking activity may contribute to active maintenance function in a range of different tasks (see Hasselmo and Stern, 2006 for review). For example, persistent spiking could contribute to delay activity observed in traditional delayed match-to-sample tasks. Neural response properties such as delay activity (Young et al, 1997; Schon et al, 2005), match enhancement, or match suppression (Young et al, 1997; Suzuki et al, 1997) can be simulated using persistent spiking in a circuit model of entorhinal cortex (Fransen et al, 2002). Cholinergic regulation of the onset of persistent spiking could provide a mechanism for gating information into active maintenance. The selective gating of information into active maintenance is necessary to perform delayed matching tasks in which a sample stimulus that must be maintained is followed by distractor stimuli that must be ignored until the test stimulus appears (Suzuki et al, 1997). Selective cholinergic activation of persistent spiking could gate just the sample stimulus into active maintenance. This is consistent with some data showing that pharmacological blockade of muscarinic cholinergic receptors impairs performance in delayed match-to-sample tasks in non-human primates (Penetar and McDonough, 1983; Miller and Desimone, 1993) and humans (Robbins et al, 1997). In working memory tasks, scopolamine does not impair tasks using the articulatory loop such as digit span (Kopelman and Corn, 1988), but does cause impairments in tasks that include interfering stimuli such as the n-back task (Green et al, 2005). Further data are needed on this topic. In unit recording studies, muscarinic blockade did not reduce match suppression in a delayed matching task, but its effect on spiking during the delay or match enhancement was not tested (Miller and Desimone, 1993). Selective lesions of the cholinergic innervation of rhinal cortex impaired delayed recognition in rats (McGaughy et al, 2005) and monkeys (Turchi et al, 2005), but cholinergic lesions of inferotemporal cortex in monkeys did not (Browning et al, 2010).

Cholinergic induction of cortical persistent spiking could underlie active maintenance of the conditioned stimulus in trace conditioning. Descriptions of this potential role for cellular mechanisms of persistent spiking (Hasselmo and Stern, 2006) motivated studies that examined the effect of cholinergic blockade on trace conditioning in rats (Bang and Brown, 2009; Esclassan et al, 2009). Consistent with the evidence for persistent spiking in entorhinal cortex, lesions of the entorhinal cortex were shown to impair trace conditioning, and local infusions of the M1 antagonist pirenzepine during conditioning impaired learning of a fear response when a stimulus was separated from a shock by a trace interval, but did not impair expression of a previously learned trace fear response (Esclassan et al, 2009). Persistent spiking has also been shown in the perirhinal cortex (Leung et al, 2006) and infusion of scopolamine into the perirhinal cortex was shown to impair trace conditioning without impairing delay conditioning (Bang and Brown, 2009). These data indicate the important role of cholinergic modulation in providing active maintenance of a conditioned stimulus during the trace interval, possibly through induction of the cellular mechanism of persistent spiking for bridging across the continuous dimension of time (Hasselmo and Stern, 2006).

Persistent spiking may contribute to the generation of responses in the sustained attention task (Sarter et al, 2005; McGaughy and Sarter, 1998). In this task, signal trials involve presentation of a panel light illuminated for $25-500 \mathrm{~ms}$, but the response to the signal cannot be generated until levers are inserted into the operant chamber, when the rat can respond to one lever indicating a signal, or a different lever indicating a nonsignal trial. The generation of a correct 'hit' response therefore requires a combination of cue detection of the signal, and maintenance of this signal for a period of time until the response can be generated. The amperometric measurement of ACh levels in this task indicates that cue detection causes a transient increase in cortical ACh levels on a time scale on the order of seconds. This transient ACh increase may specifically mediate the loading of a response into working memory through cholinergic modulation of persistent spiking, as shown in Figure 3, for maintenance until the levers enter the chamber allowing a response. If a cue-based response is already maintained by persistent spiking, then a new transient acetylcholine increase is not necessary to trigger the correct response on a subsequent hit trial, as shown in Figure 3. The regulation of persistent spiking by transient ACh allows selective gating of the cue but not other stimuli into working memory. In contrast, distractor stimuli in the sustained attention task should not evoke cholinergic transients (Himmelheber et al, 2000; Gill et al, 2000; WM Howe et al, unpublished results). Similarly, in delayed match-to-sample tasks with distractor stimuli (Miller and Desimone, 1993; Suzuki et al, 1997), the initial stimulus should be associated with a transient increase of $\mathrm{ACh}$, but the distractor stimuli should not. Alternatively, as discussed above, such challenges may increase the tonic component of cholinergic neurotransmission, thereby enhancing the gain of prefrontal glutamatergic-cholinergic interactions and thus the amplitude of cholinergic transients.

The loading of a signal or a sample stimulus into active maintenance requires temporal specificity of the cholinergic transient (Fransen et al, 2002). As pointed out above, this specificity can be obtained by local interactions between thalamic glutamatergic and cholinergic input. Sensory information during the nonsignal period or during distractor stimuli will activate glutamatergic thalamic input to 
cortical structures such as the PFC. However, in most cases this glutamatergic input will not be associated with a transient increase of acetylcholine levels. In these cases, glutamatergic synaptic input can drive cortical neurons to spike, but after the synaptic input terminates, these cells will stop spiking, and hence sensory input will not be loaded into active maintenance (see Figure $3 \mathrm{a}$ ). In contrast, a signal event will cause sufficient glutamatergic release to cause an excitatory feedback interaction with cholinergic modulation. The thalamic fiber glutamate release evokes acetylcholine release through AMPA and NMDA receptors on ACh terminals (Parikh et al, 2008), and the increased acetylcholine release can enhance glutamate release from thalamic fibers by activation of $\alpha 4 \beta 2^{*} \mathrm{nAChRs}$ on the thalamic terminals (Lambe et al, 2003; Parikh et al, 2008; Parikh et al, 2010). This results in an excitatory feedback process that drives the large transient increase in acetylcholine observed with cue detection (Parikh et al, 2007), as shown in Figure 3b. This transient increase activates postsynaptic muscarinic receptors that activate calcium-sensitive nonspecific cation currents in cortical pyramidal cells (Fransen et al, 2002), allowing them to show sustained depolarization and persistent spiking activity even after the stimulus input has terminated. This persistent spiking activity can then be maintained until the levers enter the chamber and the response is generated.

The persistent spiking mechanisms described above are consistent with fMRI studies using a delayed match-tosample task (Schon et al, 2004). fMRI activity in the entorhinal and perirhinal cortex during the delay period correlates with subsequent memory for the sample stimulus in a post-scan recognition memory task (Schon et al, 2004). Injections of scopolamine in human subjects decrease the fMRI activity in entorhinal cortex and perirhinal cortex associated with subsequent memory for the sample stimuli (Schon et al, 2005). This supports the hypothesis that muscarinic activation of persistent spiking could underlie the maintenance of activity for encoding into long-term memory (Schon et al, 2005; Hasselmo and Stern, 2006).

The transient increase in cholinergic activity during a signal could also regulate mechanisms for detecting familiarity of a stimulus. Muscarinic receptor activation causes long-term depression of synaptic efficacy (Kirkwood et al, 1999; Warburton et al, 2003). This depression of synaptic efficacy could contribute to the repetition suppression of neural responses in areas such as the perirhinal cortex (Bogacz and Brown, 2003; Warburton et al, 2003).

\section{ACETYLCHOLINE AND HIPPOCAMPAL ENCODING}

The framework described above indicates how cholinergic modulation of persistent spiking could allow encoding of information into working memory for performance of tasks ranging from delayed match to sample to trace conditioning to cue detection. This hypothesis for cholinergic regulation of active maintenance is consistent with earlier data indicating a role of cholinergic modulation in encoding into long-term episodic memory. Evidence in humans shows that infusion of muscarinic blockers impairs encoding of stimuli for subsequent free recall (Ghoneim and Mewaldt, 1975, 1977; Petersen, 1977), and cued recall (Atri et al, 2004), while sparing procedural memory (Nissen et al, 1987). In non-human primates, systemic scopolamine impairs encoding for subsequent recognition (Aigner and Mishkin, 1986), an effect that can be replicated by selective muscarinic blockade in the perirhinal cortex (Tang et al, 1997) or by cholinergic lesions of the perirhinal cortex (Turchi et al, 2005), although Browning et al (2010) did not see impaired recognition memory after cholinergic lesions of inferotemporal cortex that include perirhinal cortex.

The cholinergic innervation of the hippocampal formation has been implicated in the encoding of episodic memories. Lesions of the fornix or medial septum, which are the source of most of the cholinergic fibers innervating the hippocampus, cause profound impairments in memoryguided tasks such as spatial alternation and reversal in rats (M'Harzi et al, 1987; Givens and Olton, 1990; Ennaceur et al, 1996; Aggleton and Brown, 1999; Bussey et al, 2000), and lesions including fornix and basal forebrain impair scene learning in monkeys (Gaffan and Harrison, 1989; Easton et al, 2002). Local infusions of scopolamine into the hippocampus impair encoding of spatial information (Blokland et al, 1992; Rogers and Kesner, 2003). However, as discussed above, selective lesions of the cholinergic innervation arising from the medial septum in the rat do not show such robust effects on encoding. These lesions do not impair the traditional spatial discrimination in the water maze (Baxter et al, 1996) that is impaired by fornix lesions (Nilsson et al, 1987), and show small or transient effects in other tasks (see above). The lack of impairment with selective ACh lesions could be due to GABAergic modulation having a redundant role with cholinergic modulation, because combined lesions of both cholinergic and GABAergic input from the medial septum impair spatial memory (Pang and Nocera, 1999; Pang et al, 2001).

The cellular mechanisms of cholinergic modulation in cortical structures may be described as attentional processes in neocortical structures because they regulate entry of new sensory information into active maintenance to guide behavioral responses. Similar cellular mechanisms in circuits mediating long-term memory may be described as encoding of memory in the hippocampal formation (Hasselmo and McGaughy, 2004). With the exception of persistent spiking, cellular effects within the hippocampal formation resemble those observed in neocortical structures, and could change the dynamics of hippocampal function to enhance the encoding of new information.

On a cellular level, cholinergic modulation in the hippocampus causes effects similar to those in other cortical regions. Similar to thalamic input to neocortex, nicotinic receptor activation enhances the influence of afferent synaptic input in the hippocampus (Radcliffe and Dani, 1998; 
Giocomo and Hasselmo, 2005) including glutamatergic input to interneurons (Alkondon and Albuquerque, 2002). Muscarinic receptor activation causes suppression of recurrent excitatory connections in hippocampal region CA3 (Hasselmo et al, 1995; Vogt and Regehr, 2001; Kremin and Hasselmo, 2007) and suppresses connections from CA3 to CA1 (Hounsgaard, 1978; Valentino and Dingledine, 1981; Hasselmo and Schnell, 1994), similar to effects shown in piriform cortex (Hasselmo and Bower, 1993) and neocortex (Hsieh et al, 2000; Kimura, 2000). Muscarinic receptor activation also enhances the hippocampal pyramidal cell spiking response to afferent input (Cole and Nicoll, 1984; Madison and Nicoll, 1984). Muscarinic modulation depolarizes inhibitory interneurons while suppressing inhibitory transmission (Pitler and Alger, 1992; Patil and Hasselmo, 1999) in a manner that could enhance the response to afferent input while decreasing tonic endogenous activity.

Afterdepolarization and plateau potentials have been observed in slices of the hippocampus (Fraser and MacVicar, 1996) similar to those observed in other cortical structures (Haj-Dahmane and Andrade, 1998). However, stable intrinsic mechanisms for persistent spiking do not appear in hippocampal slice recordings, consistent with the lower spontaneous background firing rate of hippocampal neurons, suggesting that the hippocampus is less engaged with active maintenance for working memory and more engaged with encoding into long-term episodic memory. In this framework, cholinergic modulation may enhance persistent spiking in the entorhinal cortex and perirhinal cortex as a short-term buffer for new information (Hasselmo and Stern, 2006), while also enhancing the responsiveness of hippocampus to afferent input for encoding through enhanced induction of long-term potentiation. The enhancement of long-term encoding could be at least partially mediated by the cholinergic enhancement of long-term potentiation in the hippocampus (Blitzer et al, 1990; Burgard and Sarvey, 1990; Auerbach and Segal, 1994; Isaac et al, 2009).

The effects of ACh cannot be considered in terms of static patterns of activity, as the hippocampus shows complex dynamical properties including prominent field potential oscillations in the theta frequency range (Buzsaki, 2002). Cholinergic modulation may have an important role in the induction of theta rhythm oscillations (Bland and Colom, 1993). On a cellular level, acetylcholine induces theta rhythmic activity in hippocampal interneurons of stratum lacunosum-moleculare (Chapman and Lacaille, 1999). Muscarinic activation also selectively enhances the response to theta rhythmic input in interneurons projecting from stratum oriens to lacunosum-moleculare (Lawrence et al, $2006 a, b)$. In entorhinal cortex, cholinergic modulation of oscillations has been proposed to underlie the expansion of grid cell spacing in novel environments (Burgess et al, 2007), and this proposal is supported by data showing that cholinergic modulation lowers the intrinsic resonance frequency of entorhinal stellate cells (Heys et al, 2010). On a network level, cholinergic modulation of the medial septum induces theta rhythm oscillations (Lawson and Bland, 1993) and theta rhythm is correlated with higher levels of acetylcholine in the hippocampus (Marrosu et al, 1995; Monmaur et al, 1997), whereas lesions of the cholinergic innervation reduce the magnitude of theta rhythm (Lee et al, 1994). Theta rhythm oscillations might induce dynamical changes similar to the change in circuit dynamics induced by acetylcholine in the neocortex.

The cholinergic modulation of hippocampal encoding dynamics might also include selective activation of a loop through the dentate gyrus and region CA3 for encoding. The direct entorhinal projections to region CA1 have been shown to be sufficient for driving hippocampal neural activity of place cells (Mizumori et al, 1989; Brun et al, 2002). Lesions of CA3 impair both encoding and retrieval of the context of fear conditioning, whereas lesions of CA1 impair only the retrieval (Ji and Maren, 2008). Cholinergic modulation of region CA3 seems to be important for the encoding of new information. Infusion of scopolamine into CA3 impairs the encoding of information in spatial memory tasks (Rogers and Kesner, 2003) as well as fear conditioning tasks (Rogers and Kesner, 2004), possibly by reducing the depolarization of CA3 neurons and the induction of longterm potentiation. Cholinergic modulation also affects the functional activation of the dentate gyrus, as infusion of acetylcholine into the dentate gyrus enhances the population spike response to perforant pathway stimulation (Foster and Deadwyler, 1992). The cholinergic enhancement of encoding of sensory stimuli might be coupled with a reduction in the retrieval mediated by internal feedback influences, as suggested by the reduction of evoked synaptic potentials in CA1 during acetylcholine infusion (Herreras et al, 1988) and during behavioral states associated with higher levels of acetylcholine such as REM sleep (Winson and Abzug, 1977, 1978; Hasselmo, 1999). Consistent with this, the AChE inhibitor physostigmine reduces behavioral retrieval of previous learning (Rogers and Kesner, 2003, 2004), suggesting that cholinergic modulation reduces the influence of retrieval. Physostigmine also impairs consolidation (Gais and Born, 2004) and scopolamine enhances consolidation (Rasch et al, 2006), consistent with the theory that lower levels of ACh during slow-wave sleep might allow enhanced feedback appropriate for consolidation (Hasselmo, 1999).

Recent computational modeling shows how a circuit including grid cells, place cells, and head direction cells could mediate the encoding and retrieval of spatiotemporal trajectories for episodic memory (Hasselmo, 2008b, 2009). These models require a shift in the dynamics of the network between encoding and retrieval, in which the encoding of new information involves enhancement of long-term potentiation at intrinsic connections of the hippocampus and at connections from the hippocampus to the postsubiculum. During encoding the synapses being modified must not influence their postsynaptic target, to avoid distorting the stored representation (Hasselmo and Bower, 1992, 1993; Hasselmo and Schnell, 1994). In contrast, during 
retrieval, the previously modified synapses must have a stronger influence to drive retrieval of a trajectory within the network. This transition from encoding to retrieval could be mediated by changes in cholinergic neurotransmission on a time scale of the sort shown with amperometry in the neocortex (Parikh et al, 2007).

In summary, the cellular effects of acetylcholine are similar within the hippocampal formation and the neocortex. The behavioral effect of this cholinergic modulation might depend on the nature of the processing in local circuits. Cholinergic modulation of cellular properties in the neocortex might switch dynamics from a default state to a state of fostering cue detection. Enhancement of persistent spiking might gate sensory information into working memory for the active maintenance of future responses. The enhancement of afferent input to the hippocampus might enhance encoding into long-term episodic memory, whereas the enhancement of the response to thalamic input to the neocortex might enhance attention to sensory stimuli.

\section{FUTURE RESEARCH DIRECTIONS: TOWARD A NEW CHOLINERGIC NEUROPSYCHOPHARMACOLOGY}

We began this article by pointing to the limitations of conventional neuropsychopharmacological tools to probe the cognitive functions of the cholinergic system and to assess the usefulness of cholinergic treatments for the cognitive impairments on a wide range of disorders. Although our understanding of the regulation and function of cholinergic systems remains rudimentary, research has indicated that cholinergic systems act in strikingly more complex ways than was assumed just a decade ago. It is likely that different yet complementary functions are mediated by cholinergic signaling mechanisms that occur on different time scales (seconds $v s$ minutes). Furthermore, it seems that within a major branch of the brain's cholinergic systems there is substantially greater topographic differentiation than originally assumed, and that the potentially highly specific functions of ACh within a particular target region are based in part on highly topographic projection systems. Moreover, the cognitive selectivity of the effects of cholinergic modulation may be largely determined by the target circuit, based on local microcircuitry controlling cholinergic presynaptic activity, through heteroreceptors expressed on cholinergic terminals.

Such a description of the cholinergic system may suggest daunting challenges for efforts to develop new cholinergic therapies. Certainly, these complexities may explain in part the limitations of conventional approaches, such as elevating ACh levels through AChE inhibition or direct stimulation of mAChRs (see Introduction). However, the new evidence and related circuitry models also provide the basis for new and innovative approaches to enhance cholinergic function. Most obviously, we can stimulate $\alpha 4 \beta 2^{*}$ nAChRs to amplify cholinergic transients and enhance attentional performance (eg, Howe et al, 2010). Although the clinical evidence remains limited, some evidence supports the view that such compounds may be useful for treating the cognitive symptoms of ADHD, schizophrenia, and aging (Dunbar et al, 2007; Wilens et al, 1999, 2006; Wilens and Decker, 2007; Potter et al, 1999). Other nAChR subunits are likely to modulate the gain in other aspects of cortical circuitry (eg, Dickinson et al, 2008) and thus may similarly be found to modulate relatively specific aspects of information processing.

The potential clinical significance of $\alpha 7 \mathrm{nAChR}$ agonists is more difficult to predict. As pointed out above, our own evidence does not allow deduction of a specific hypothesis about the cognitive functions that may benefit from stimulation of these receptors. To the contrary, we find that removing the contribution of these receptors to the effects of nicotine transforms nicotine into a more efficacious enhancer of attentional performance (Howe et al, 2010). The treatment of the cognitive symptoms of schizophrenia has been a focus of $\alpha 7 \mathrm{nAChR}$ agonists; however, their potential utility remains to be determined (eg, Martin et al, 2004; Freedman et al, 2008).

As discussed above, our understanding of the potential therapeutic significance of $\mathrm{mAChR}$ agonists has remained poor, perhaps largely because of the paucity of ligands available for probing $\mathrm{mAChR}$ subtypes (eg, Wienrich et al, 2002; Bodick et al, 1997; Raffaele et al, 1996). New, selective ligands are becoming available now, allowing the test of the hypothesis that mAChRs control mechanisms that concern the maintenance of the state of prefrontal circuits and the recruitment of efferent projections in situations requiring top-down control of cognitive performance.

Emerging positive allosteric modulators (PAMs) for both nAChRs and mAChRs (Shirey et al, 2009; Hurst et al, 2005; Taly et al, 2009) allow addressing particularly important questions. The promise for such ligands is based on the general assumption that modification of an endogenous signal represents a superior approach to cognitive enhancement when contrasted against introducing a pharmacological signal to influence circuit functions (Sarter and Bruno 1997). Although the potential efficacy of such a strategy may be limited by structural alterations in brain circuitry, PAMs acting at AChRs are expected to afford a level of modulatory selectivity and temporal precision that will not only assist in revealing the precise role of cholinergic systems in a particular behavioral or cognitive context, but also may allow the manifestation of effect sizes that are of clinical relevance. For example, PAMs targeted at M4 receptors may allow selective suppression of glutamatergic excitatory transmission (Shirey et al, 2008) to enhance the specificity of neural firing and synaptic modification without causing excess activation of excitatory postsynaptic M1 receptors.

The administration of cholinergic drugs as a co-treatment will be a clinical necessity for many indications, including for treating the cognitive symptoms of schizophrenia. With the exception of studies on donepezil as a co-treatment in 
schizophrenia (eg, Keefe et al, 2008; Kohler et al, 2007), neuropsychopharmacological, and specifically preclinical, research on such co-treatment strategies has received little attention, perhaps due to a considerable part to the regulatory and commercial challenges associated with the development of combination treatments. However, it seems paramount that such approaches be investigated to determine the true clinical potential of new cholinergic drugs.

Finally, the importance of interactions between new cholinergic treatments and cognitive practice for revealing the full efficacy of treatments deserves reiteration. As previously discussed (Sarter and Bruno 1997), treating, for example, heart disease is commonly expected to consist of combinations of pharmacological and behavioral therapies (see also Keefe et al, 2010). In contrast, treatments of cognitive disorders often are expected to consist solely of the administration of a pharmacological 'magic bullet'. Selective $\mathrm{n} / \mathrm{mAChR}$ agonists and PAMs at these receptors may come as close to magic bullets as can be currently envisioned. However, obtaining their full benefit requires that they interact with cognitive demand-induced recruitment of forebrain circuitry. Conducting clinical trials that seek to show interactions between the effects of a pharmacological treatment and cognitive practice may not constitute an exotic, luxurious effort but perhaps a psychopharmacological necessity for discovering truly effective treatments for cognitive impairments.

\section{ACKNOWLEDGEMENTS}

Our research was supported by the PHS Grants RO1 MH61492 (to MEH), R01 MH60013 (to MEH) and Silvio O. Conte Center MH71702 (to MEH) and R01 MH080332 (to MS), R21 MH080426 (to MS) and R01 MH086530 (to MS).

\section{DISCLOSURE}

Dr Michael Hasselmo has no conflict of interest.

Dr Martin Sarter has received honoraria for speaking at Abbott Laboratories, Pfizer Pharmaceuticals, and Lilly UK, and has received research support from Abbott Laboratories, Pfizer Pharmaceuticals, and Institut de Recherches Internationales Servier.

\section{REFERENCES}

Aarsland D, Larsen JP, Reinvang I, Aasland AM (1994). Effects of cholinergic blockade on language in healthy young women. Brain 117: 1377-1384.

Aggleton JP, Brown MW (1999). Episodic memory, amnesia, and the hippocampalanterior thalamic axis. Behav Brain Sci 22: 425-444.

Aigner TG, Mishkin M (1986). The effects of physostigmine and scopolamine on recognition memory in monkeys. Behav Neurosci 45: 81-87.

Aigner TG, Mitchell SJ, Aggleton JP, DeLong MR, Struble RG, Price DL et al (1987). Effects of scopolamine and physostigmine on recognition memory in monkeys with ibotenic-acid lesions of the nucleus basalis of Meynert. Psychopharmacology 92: 292-300.

Aigner TG, Walker DL, Mishkin M (1991). Comparison of the effects of scopolamine administered before and after acquisition in a test of visual recognition memory in monkeys. Behav Neural Biol 55: 61-67.
Alkondon M, Albuquerque EX (2002). A non-alpha7 nicotinic acetylcholine receptor modulates excitatory input to hippocampal CA1 interneurons. J Neurophysio/ 87: 1651-1654.

Arnold HM, Burk JA, Hodgson EM, Sarter M, Bruno JP (2002). Differential cortical acetylcholine release in rats performing a sustained attention task versus behavioral control tasks that do not explicitly tax attention. Neuroscience 114: 451-460.

Atri A, Sherman S, Norman KA, Kirchhoff BA, Nicolas MM, Greicius MD et al (2004). Blockade of central cholinergic receptors impairs new learning and increases proactive interference in a word paired-associate memory task. Behav Neurosci 118: 223-236.

Auerbach JM, Segal M (1994). A novel cholinergic induction of long-term potentiation in rat hippocampus. J Neurophysiol 72: 2034-2040.

Azam L, Winzer-Serhan U, Leslie FM (2003). Co-expression of alpha7 and beta2 nicotinic acetylcholine receptor subunit mRNAs within rat brain cholinergic neurons. Neuroscience 119: 965-977.

Bandyopadhyay S, Sutor B, Hablitz JJ (2006). Endogenous acetylcholine enhances synchronized interneuron activity in rat neocortex. J Neurophysiol 95: 1908-1916.

Bang SJ, Brown TH (2009). Muscarinic receptors in perirhinal cortex control trace conditioning. J Neurosci 29: 4346-4350. Demonstration that muscarinic cholinergic receptor blockade in perirhinal cortex with scopolamine impairs behavior dependent on the capacity to maintain information about the conditional stimulus over a trace interval.

Barkai E, Hasselmo ME (1994). Modulation of the input/output function of rat piriform cortex pyramidal cells. J Neurophysiol 72: 644-658.

Bartus RT (2000). On neurodegenerative diseases, models, and treatment strategies: lessons learned and lessons forgotten a generation following the cholinergic hypothesis. Exp Neurol 163: 495-529.

Baxter MG, Bucci DJ, Gorman LK, Wiley RG, Gallagher M (1995). Selective immunotoxic lesions of basal forebrain cholinergic cells: effects on learning and memory in rats. Behav Neurosci 109: 714-722.

Baxter MG, Bucci DJ, Holland PC, Gallagher M (1999). Impairments in conditioned stimulus processing and conditioned responding after combined selective removal of hippocampal and neocortical cholinergic input. Behav Neurosci 113: 486-495.

Baxter MG, Bucci DJ, Sobel TJ, Williams MJ, Gorman LK, Gallagher M (1996). Intact spatial learning following lesions of basal forebrain cholinergic neurons. NeuroReport 7: 1417-1420.

Beatty WW, Butters N, Janowsky DS (1986). Patterns of memory failure after scopolamine treatment: implications for cholinergic hypotheses of dementia. Behav Neural Biol 45: 196-211.

Behrends JC, ten Bruggencate G (1993). Cholinergic modulation of synaptic inhibition in the guinea pig hippocampus in vitro: excitation of GABAergic interneurons and inhibition of GABA-release. J Neurophysiol 69: 626-629.

Bentley P, Driver J, Dolan RJ (2008). Cholinesterase inhibition modulates visual and attentional brain responses in Alzheimer's disease and health. Brain 131: 409-424.

Bentley P, Driver J, Dolan RJ (2009). Modulation of fusiform cortex activity by cholinesterase inhibition predicts effects on subsequent memory. Brain 132: 2356-2371.

Bentley P, Husain M, Dolan RJ (2004). Effects of cholinergic enhancement on visual stimulation, spatial attention, and spatial working memory. Neuron 41: 969-982. This pharmaco-fMRI study demonstrates that physostigmine increases extrastriate occipital cortex activation selectively during maintained attention and working memory encoding

Bentley P, Vuilleumier P, Thiel CM, Driver J, Dolan RJ (2003). Effects of attention and emotion on repetition priming and their modulation by cholinergic enhancement. J Neurophysiol 90: 1171-1181.

Berg DK, Conroy WG (2002). Nicotinic alpha 7 receptors: synaptic options and downstream signaling in neurons. J Neurobiol 53: 512-523.

Bitner RS, Bunnelle WH, Anderson DJ, Briggs CA, Buccafusco J, Curzon P et al (2007). Broad-spectrum efficacy across cognitive domains by alpha7 nicotinic acetylcholine receptor agonism correlates with activation of ERK1/2 and CREB phosphorylation pathways. J Neurosci 27: 10578-10587.

Bland BH, Colom LV (1993). Extrinsic and intrinsic properties underlying oscillation and synchrony in limbic cortex. Prog Neurobiol 41: 157-208.

Blitzer RD, Gil O, Landau EM (1990). Cholinergic stimulation enhances longterm potentiation in the CA1 region of rat hippocampus. Neurosci Lett 119: 207-210.

Blokland A, Honig W, Raaijmakers WGM (1992). Effects of intra-hippocampal scopolamine injections in a repeated spatial acquisition task in the rat. Psychopharmacology 109: 373-376.

Bodick NC, Offen WW, Levey Al, Cutler NR, Gauthier SG, Satlin A et al (1997). Effects of xanomeline, a selective muscarinic receptor agonist on cognitive 
function and behavioral symptoms in Alzheimer's disease. Arch Neurol 54: 465-473.

Bogacz R, Brown MW (2003). Comparison of computational models of familiarity discrimination in the perirhinal cortex. Hippocampus 13: 494-524.

Botly LC, De Rosa E (2009). Cholinergic deafferentation of the neocortex using 192 IgG-saporin impairs feature binding in rats. J Neurosci 29: 4120-4130.

Bozzali M, MacPherson SE, Dolan RJ, Shallice T (2006). Left prefrontal cortex control of novel occurrences during recollection: a psychopharmacological study using scopolamine and event-related fMRI. Neuroimage 33: 286-295.

Briand LA, Gritton H, Howe WM, Young DA, Sarter M (2007). Modulators in concert for cognition: modulator interactions in the prefrontal cortex. Prog Neurobio/ 83: 69-91.

Broks P, Preston GC, Traub M, Poppleton P, Ward C, Stahl SM (1988). Modelling dementia: effects of scopolamine on memory and attention. Neuropsychologia 26: $685-700$

Broussard Jl, Karelina K, Sarter M, Givens B (2009). Cholinergic optimization of cue-evoked parietal activity during challenged attentional performance. Eur J Neurosci 29: 1711-1722.

Browning PG, Gaffan D, Croxson PL, Baxter MG (2010). Severe scene learning impairment, but intact recognition memory, after cholinergic depletion of inferotemporal cortex followed by fornix transection. Cereb Cortex 20: 282-293.

Brun VH, Otnass MK, Molden S, Steffenach HA, Witter MP, Moser MB et al (2002). Place cells and place recognition maintained by direct entorhinal-hippocampal circuitry. Science 296: 2243-2246.

Burgard EC, Sarvey JM (1990). Muscarinic receptor activation facilitates the induction of long-term potentiation (LTP) in the rat dentate gyrus. Neurosci Lett 116: 34-39.

Burgess N, Barry C, O’Keefe J (2007). An oscillatory interference model of grid cell firing. Hippocampus 17: 801-812.

Burmeister JJ, Moxon K, Gerhardt GA (2000). Ceramic-based multisite microelectrodes for electrochemical recordings. Anal Chem 72: 187-192.

Bussey TJ, Duck J, Muir JL, Aggleton JP (2000). Distinct patterns of behavioural impairments resulting from fornix transection or neurotoxic lesions of the perirhinal and postrhinal cortices in the rat. Behav Brain Res 111: 187-202.

Buzsaki G (2002). Theta oscillations in the hippocampus. Neuron 33: 325-340.

Chapman CA, Lacaille JC (1999). Cholinergic induction of theta-frequency oscillations in hippocampal inhibitory interneurons and pacing of pyramidal cell firing. J Neurosci 19: 8637-8645.

Chappell J, McMahan R, Chiba AA, Gallagher M (1998). A re-examination of the role of basal forebrain cholinergic neurons in spatial working memory. Neuropharmacol 37: 481-487.

Chen KC, Baxter MG, Rodefer JS (2004). Central blockade of muscarinic cholinergic receptors disrupts affective and attentional set-shifting. Eur J Neurosci 20: 1081-1088

Chiba AA, Bucci DJ, Holland PC, Gallagher M (1995). Basal forebrain cholinergic lesions disrupt increments but not decrements in conditioned stimulus processing. J Neurosci 15: 7315-7322.

Chiba AA, Bushnell PJ, Oshiro WM, Gallagher M (1999). Selective removal of cholinergic neurons in the basal forebrain alters cued target detection. NeuroReport 29: 3119-3123.

Christensen H, Maltby N, Jorm AF, Creasey H, Broe GA (1992). Cholinergic blockade as a model of the cognitive deficits in Alzheimer's disease. Brain 115: 1681-1699.

Christophe E, Roebuck A, Staiger JF, Lavery DJ, Charpak S, Audinat E (2002). Two types of nicotinic receptors mediate an excitation of neocortical layer I interneurons. J Neurophysio/ 88: 1318-1327.

Cole AE, Nicoll RA (1984). Characterization of a slow cholinergic postsynaptic potential recorded in vitro from rat hippocampal pyramidal cells. J Physiol (London) 352: 173-188.

Crick F (1984). Function of the thalamic reticular complex: the searchlight hypothesis. Proc Natl Acad Sci USA 81: 4586-4590.

Dalley JW, McGaughy J, O'Connell MT, Cardinal RN, Levita L, Robbins TW (2001). Distinct changes in cortical acetylcholine and noradrenaline efflux during contingent and noncontingent performance of a visual attentional task. J Neurosci 21: 4908-4914.

Dalley JW, Theobald DE, Bouger P, Chudasama Y, Cardinal RN, Robbins TW (2004). Cortical cholinergic function and deficits in visual attentional performance in rats following 192 lgG-saporin-induced lesions of the medial prefrontal cortex. Cereb Cortex 14: 922-932.

Davidson MC, Cutrell EB, Marrocco RT (1999). Scopolamine slows the orienting of attention in primates to cued visual targets. Psychopharmacology 142: 1-8.

Davidson MC, Marrocco RT (2000). Local infusion of scopolamine into intraparietal cortex slows covert orienting in rhesus monkeys. J Neurophysio/ 83: 1536-1549.

Deco G, Thiele A (2009). Attention - oscillations and neuropharmacology. Eur J Neurosci 30: 347-354.
Deutsch JA (1971). The cholinergic synapse and the site of memory. Science 174 788-794.

Deutsch JA, Rocklin KW (1967). Amnesia induced by scopolamine and its temporal variations. Nature 216: 89-90.

Dickinson JA, Kew JN, Wonnacott S (2008). Presynaptic alpha 7- and beta 2-containing nicotinic acetylcholine receptors modulate excitatory amino acid release from rat prefrontal cortex nerve terminals via distinct cellular mechanisms. Mol Pharmacol 74: 348-359.

Disney AA, Aoki C (2008). Muscarinic acetylcholine receptors in macaque V1 are most frequently expressed by parvalbumin-immunoreactive neurons. J Comp Neurol 507: 1748-1762.

Disney AA, Aoki C, Hawken MJ (2007). Gain modulation by nicotine in macaque v1. Neuron 56: 701-713. An important study in primates demonstrating that stimulation of nicotinic acetylcholine receptors in the visual cortex enhances cue detection.

Drachman DA (1977). Memory and cognitive function in man: does the cholinergic system have a specific role? Neurology 27: 783-790.

Drachman DA, Sahakian BJ (1980). Memory and cognitive function in the elderly. A preliminary trial of physostigmine. Arch Neurol 37: 674-675.

Duffy AM, Zhou P, Milner TA, Pickel VM (2009). Spatial and intracellular relationships between the alpha7 nicotinic acetylcholine receptor and the vesicular acetylcholine transporter in the prefrontal cortex of rat and mouse. Neuroscience 161: 1091-1103.

Dunbar GC, Inglis F, Kuchibhatla R, Sharma T, Tomlinson M, Wamsley J (2007). Effect of ispronicline, a neuronal nicotinic acetylcholine receptor partial agonist, in subjects with age associated memory impairment (AAMI). J Psychopharmacol 21: $171-178$

Dunne MP, Hartley LR (1986). Scopolamine and the control of attention in humans. Psychopharmacology 89: 94-97.

Dunnett SB, Everitt BJ, Robbins TW (1991). The basal forebrain-cortical cholinergic system: interpreting the functional consequences of excitotoxic lesions. Trends Neurosci 14: 494-501.

Easton A, Ridley RM, Baker HF, Gaffan D (2002). Unilateral lesions of the cholinergic basal forebrain and fornix in one hemisphere and inferior temporal cortex in the opposite hemisphere produce severe learning impairments in rhesus monkeys. Cereb Cortex 12: 729-736.

Egorov AV, Hamam BN, Fransen E, Hasselmo ME, Alonso AA (2002). Graded persistent activity in entorhinal cortex neurons. Nature 420: 173-178. The first demonstration of cholinergic activation of cellular mechanisms for maintaining graded frequencies of persistent spiking

Ellis JR, Ellis KA, Bartholomeusz CF, Harrison BJ, Wesnes KA, Erskine FF et al (2006). Muscarinic and nicotinic receptors synergistically modulate working memory and attention in humans. Int J Neuropsychopharmacol 9: 175-189.

Ennaceur A, Neave N, Aggleton JP (1996). Neurotoxic lesions of the perirhinal cortex do not mimic the behavioural effects of fornix transection in the rat. Behav Brain Res 80: 9-25.

Erskine FF, Ellis JR, Ellis KA, Stuber E, Hogan K, Miller V et al (2004). Evidence for synergistic modulation of early information processing by nicotinic and muscarinic receptors in humans. Human Psychopharmacol Clin Exp 19: 503-509.

Esclassan F, Coutureau E, Di Scala G, Marchand AR (2009). A cholinergicdependent role for the entorhinal cortex in trace fear conditioning. J Neurosci 29 8087-8093. Demonstrates the specific role of entorhinal cortex in trace conditioning, and shows that local infusion of an M1 antagonist impairs trace conditioning

Fibiger HC (1991). Cholinergic mechanisms in learning, memory and dementia: a review of recent evidence. Trends Neurosci 14: 220-223.

Flicker C, Feris SH, Serby M (1992). Hypersensitivity to scopolamine in the elderly. Psychopharmacology 107: 437-441.

Foldi NS, White RE, Schaefer LA (2005). Detecting effects of donepezil on visual selective attention using signal detection parameters in Alzheimer's disease. Int J Geriatr Psychiat 20: 485-488.

Foster TC, Deadwyler SA (1992). Acetylcholine modulates averaged sensory evoked responses and perforant path evoked field potentials in the rat dentate gyrus. Brain Res 587: 95-101.

Fransen E, Alonso AA, Hasselmo ME (2002). Simulations of the role of the muscarinicactivated calcium-sensitive nonspecific cation current INCM in entorhinal neuronal activity during delayed matching tasks. J Neurosci 22: 1081-1097.

Fransen E, Tahvildari B, Egorov AV, Hasselmo ME, Alonso AA (2006). Mechanism of graded persistent cellular activity of entorhinal cortex layer $v$ neurons. Neuron 49 735-746

Fraser DD, MacVicar BA (1996). Cholinergic-dependent plateau potential in hippocampal CA1 pyramidal neurons. J Neurosci 16: 4113-4128.

Freedman R, Olincy A, Buchanan RW, Harris JG, Gold JM, Johnson L et al (2008). Initial phase 2 trial of a nicotinic agonist in schizophrenia. Am J Psychiatry 165: $1040-1047$. 
Frick KM, Kim JJ, Baxter MG (2004). Effects of complete immunotoxin lesions of the cholinergic basal forebrain on fear conditioning and spatial learning. Hippocampus 14: 244-254.

Furey ML, Pietrini P, Haxby JV (2000). Cholinergic enhancement and increased selectivity of perceptual processing during working memory. Science 290: 2315-2319.

Furey ML, Pietrini P, Haxby JV, Drevets WC (2008). Selective effects of cholinergic modulation on task performance during selective attention. Neuropsychopharmacology 33: 913-923.

Gaffan D, Harrison S (1989). Place memory and scene memory: effects of fornix transection in the monkey. Exp Brain Res 74: 202-212.

Gais S, Born J (2004). Low acetylcholine during slow-wave sleep is critical for declarative memory consolidation. Proc Natl Acad Sci USA 101: 2140-2144.

Galani R, Lehmann O, Bolmont T, Aloy E, Bertrand F, Lazarus C et al (2002). Selective immunolesions of $\mathrm{CH} 4$ cholinergic neurons do not disrupt spatial memory in rats. Physiol Behav 76: 75-90.

Ghoneim MM, Mewaldt SP (1975). Effects of diazepam and scopolamine on storage, retrieval and organizational processes in memory. Psychopharmacologia 44: 257-262.

Ghoneim MM, Mewaldt SP (1977). Studies on human memory: the interactions of diazepam, scopolamine, and physostigmine. Psychopharmacology 52: 1-6.

Giessing C, Fink GR, Rosler F, Thiel CM (2007). fMRI data predict individual differences of behavioral effects of nicotine: a partial least square analysis. J Cogn Neurosci 19: 658-670.

Giessing C, Thiel CM, Rosler F, Fink GR (2006). The modulatory effects of nicotine on parietal cortex activity in a cued target detection task depend on cue reliability. Neuroscience 137: 853-864.

Gil Z, Conners BW, Amitai Y (1997). Differential regulation of neocortical synapses by neuromodulators and activity. Neuron 19: 679-686. This study showed nicotinic enhancement of thalamocortical glutamatergic synaptic transmission along with muscarinic suppression of intracortical glutamatergic transmission.

Gill TM, Sarter M, Givens B (2000). Sustained visual attention performanceassociated prefrontal neuronal activity: evidence for cholinergic modulation. J Neurosci 20: 4745-4757.

Gioanni Y, Rougeot C, Clarke PB, Lepouse C, Thierry AM, Vidal C (1999). Nicotinic receptors in the rat prefrontal cortex: increase in glutamate release and facilitation of mediodorsal thalamo-cortical transmission. Eur J Neurosci 11: 18-30.

Giocomo LM, Hasselmo ME (2005). Nicotinic modulation of glutamatergic synaptic transmission in region CA3 of the hippocampus. Eur J Neurosci 22: 1349-1356.

Giuliano C, Parikh V, Ward JR, Chiamulera C, Sarter M (2008). Increases in cholinergic neurotransmission measured by using choline-sensitive microelectrodes: enhanced detection by hydrolysis of acetylcholine on recording sites? Neurochem Int 52: 1343-1350.

Givens BS, Olton DS (1990). Cholinergic and GABAergic modulation of the medial septal area: effect on working memory. Behav Neurosci 104: 849-855.

Grasby PM, Frith CD, Paulesu E, Friston KJ, Frackowiak RS, Dolan RJ (1995). The effect of the muscarinic antagonist scopolamine on regional cerebral blood flow during the performance of a memory task. Exp Brain Res 104: 337-348.

Gray R, Rajan AS, Radcliffe KA, Yakehiro M, Dani JA (1996). Hippocampal synaptic transmission enhanced by low concentrations of nicotine. Nature 383: 713-716.

Green A, Ellis KA, Ellis J, Bartholomeusz CF, llic S, Croft RJ et al (2005). Muscarinic and nicotinic receptor modulation of object and spatial n-back working memory in humans. Pharmacol Biochem Behav 81: 575-584.

Greenwood PM, Lin MK, Sundararajan R, Fryxell KJ, Parasuraman R (2009). Synergistic effects of genetic variation in nicotinic and muscarinic receptors on visual attention but not working memory. Proc Natl Acad Sci USA 106: 3633-3638.

Grottick AJ, Higgins GA (2000). Effect of subtype selective nicotinic compounds on attention as assessed by the five-choice serial reaction time task. Behav Brain Res 117: 197-208.

Guillery RW, Feig SL, Lozsadi DA (1998). Paying attention to the thalamic reticular nucleus. Trends Neurosci 21: 28-32.

Gulledge AT, Bucci DJ, Zhang SS, Matsui M, Yeh HH (2009). M1 receptors mediate cholinergic modulation of excitability in neocortical pyramidal neurons. J Neurosci 28: 9888-9902.

Gulledge AT, Stuart GJ (2005). Cholinergic inhibition of neocortical pyramidal neurons. J Neurosci 25: 10308-10320.

Hahn B, Sharples CG, Wonnacott S, Shoaib M, Stolerman IP (2003). Attentional effects of nicotinic agonists in rats. Neuropharmacology 44: 1054-1067.

Haj-Dahmane S, Andrade R (1996). Muscarinic activation of a voltage-dependent cation nonselective current in rat association cortex. J Neurosci 16: 3848-3861.

Haj-Dahmane S, Andrade R (1997). Calcium-activated cation nonselective current contributes to the fast afterdepolarization in rat prefrontal cortex neurons. J Neurophysiol 78: 1983-1989.
Haj-Dahmane S, Andrade R (1998). Ionic mechanism of the slow afterdepolarization induced by muscarinic receptor activation in rat prefrontal cortex. J Neurophysiol 80: 1197-1210. Study showing potential cellular mechanisms for cholinergic induction of persistent spiking in neocortical structures.

Hallanger AE, Levey Al, Lee HJ, Rye DB, Wainer BH (1987). The origins of cholinergic and other subcortical afferents to the thalamus in the rat. $J$ Comp Neurol 262: 105-124.

Hasselmo ME (1999). Neuromodulation: acetylcholine and memory consolidation. Trends Cogn Sci 3: 351-359.

Hasselmo ME (2006). The role of acetylcholine in learning and memory. Curr Opin Neurobiol 16: 710-715

Hasselmo ME (2008). Temporally structured replay of neural activity in a model of entorhinal cortex, hippocampus and postsubiculum. Eur J Neurosci 28: 1301-1315.

Hasselmo ME (2009). A model of episodic memory: mental time travel along encoded trajectories using grid cells. Neurobiol Learn Mem 92: 559-573.

Hasselmo ME, Anderson BP, Bower JM (1992). Cholinergic modulation of cortical associative memory function. J Neurophysiol 67: 1230-1246.

Hasselmo ME, Bower JM (1992). Cholinergic suppression specific to intrinsic not afferent fiber synapses in rat piriform (olfactory) cortex. J Neurophysiol 67: 1222-1229. First study showing selective muscarinic presynaptic inhibition of synaptic transmission at intracortical synapses with sparing of transmission at afferent synapses bringing sensory information into the cortex.

Hasselmo ME, Bower JM (1993). Acetylcholine and memory. Trends Neurosci 16: 218-222.

Hasselmo ME, Cekic M (1996). Suppression of synaptic transmission may allow combination of associative feedback and self-organizing feedforward connections in the neocortex. Behav Brain Res 79: 153-161.

Hasselmo ME, McGaughy J (2004). High acetylcholine levels set circuit dynamics for attention and encoding and low acetylcholine levels set dynamics for consolidation. Prog Brain Res 145: 207-231.

Hasselmo ME, Schnell E (1994). Laminar selectivity of the cholinergic suppression of synaptic transmission in rat hippocampal region CA1: computational modeling and brain slice physiology. J Neurosci 14: 3898-3914.

Hasselmo ME, Schnell E, Barkai E (1995). Dynamics of learning and recall at excitatory recurrent synapses and cholinergic modulation in rat hippocampal region CA3. J Neurosci 15: 5249-5262.

Hasselmo ME, Stern CE (2006). Mechanisms underlying working memory for novel information. Trends Cogn Sci 10: 487-493.

Herreras O, Solis JM, Herranz AS, Martin del Rio R, Lerma J (1988). Sensory modulation of hippocampal transmission. II. Evidence for a cholinergic locus of inhibition in the Schaffer-CA1 synapse. Brain Res 461: 303-313.

Herrero JL, Roberts MJ, Delicato LS, Gieselmann MA, Dayan P, Thiele A (2008). Acetylcholine contributes through muscarinic receptors to attentional modulation in V1. Nature 454: 1110-1114. This study is one of the rare experiments that indicates a key role of muscarinic AChRs in the regulation of attentional effects in a primary sensory region of non-human primates.

Herzog CD, Nowak KA, Sarter M, Bruno JP (2003). Microdialysis without acetylcholinesterase inhibition reveals an age-related attenuation in stimulated cortical acetylcholine release. Neurobiol Aging 24: 861-863.

Heys JG, Giocomo LM, Hasselmo ME (2010). Cholinergic modulation of the resonance properties of stellate cells in layer II of medial entorhinal cortex. J Neurophysiol 104: 258-270.

Himmelheber AM, Sarter M, Bruno JP (1997). Operant performance and cortical acetylcholine release: role of response rate, reward density, and non-contingent stimuli. Brain Res Cogn Brain Res 6: 23-36.

Himmelheber AM, Sarter M, Bruno JP (2000). Increases in cortical acetylcholine release during sustained attention performance in rats. Cogn Brain Res 9: 313-325.

Hounsgaard J (1978). Presynaptic inhibitory action of acetylcholine in area CA1 of the hippocampus. Exp Neurol 62: 787-797.

Howe WM, Ji J, Parikh V, Williams S, Mocaer E, Trocme-Thibierge C et al (2010). Enhanced attentional performance by selective stimulation of $\alpha 4 \beta 2^{*}$ nAChRs: underlying cholinergic mechanisms. Neuropsychopharmacology 35 : 1391-1401. This study demonstrates that blocking the $\alpha 7$ nAChR transforms nicotine into a more efficacious enhancer of attention, due to the 'sharpening' of nicotine-evoked cholinergic transients.

Howe WM, Parikh V, Martinez V, Sarter M (2007). Prefrontal cholinergic switching from associational processing to cue detection: evidence from sub-second measures of prefrontal cholinergic neurotransmission, using choline-sensitive microelectrodes, in animals performing an operant sustained attention task. Society for Neuroscience Annual Meeting: San Diego, CA.

Hoyle E, Genn RF, Fernandes C, Stolerman IP (2006). Impaired performance of alpha7 nicotinic receptor knockout mice in the five-choice serial reaction time task. Psychopharmacology (Berl) 189: 211-223. 
Hsieh CY, Cruikshank SJ, Metherate R (2000). Differential modulation of auditory thalamocortical and intracortical synaptic transmission by cholinergic agonist. Brain Res 880: 51-64.

Huff FJ, Mickel SF, Corkin S, Growdon JH (1988). Cognitive functions affected by scopolamine in Alzheimer's disease and normal aging. Drug Develop Res 12: 271-278.

Hurst RS, Hajos M, Raggenbass M, Wall TM, Higdon NR, Lawson JA et al (2005). A novel positive allosteric modulator of the alpha7 neuronal nicotinic acetylcholine receptor: in vitro and in vivo characterization. J Neurosci 25: 4396-4405.

Hyman BT, Van Hoesen GW, Damasio AR, Barnes CL (1984). Alzheimer's disease: cell-specific pathology isolates the hippocampal formation. Science 225: 1168-1170.

Isaac JT, Buchanan KA, Muller RU, Mellor JR (2009). Hippocampal place cell firing patterns can induce long-term synaptic plasticity in vitro. J Neurosci 29: 6840-6850.

Ji J, Maren S (2008). Differential roles for hippocampal areas CA1 and CA3 in the contextual encoding and retrieval of extinguished fear. Learn Mem 15: 244-251.

Keefe RS, Malhotra AK, Meltzer HY, Kane JM, Buchanan RW, Murthy A et al (2008). Efficacy and safety of donepezil in patients with schizophrenia or schizoaffective disorder: significant placebo/practice effects in a 12-week, randomized, double-blind, placebo-controlled trial. Neuropsychopharmacology 33: 1217-1228.

Keefe RSE, Vinogradov S, Medalia A, Silverstein SM, Bell MD, Dickinson D et al (2010). Report form the working group conference on multisite trial design for cognitive remediation in schizophrenia. Schizophren Bull, in press (e-pub ahead of print).

Kimura F (2000). Cholinergic modulation of cortical function: a hypothetical role in shifting the dynamics in cortical network. Neurosci Res 38: 19-26.

Kimura F, Baughman RW (1997). Distinct muscarinic receptor subtypes suppress excitatory and inhibitory synaptic responses in cortical neurons. J Neurophysiol 77: 709-716.

Kirkwood A, Rozas C, Kirkwood J, Perez F, Bear MF (1999). Modulation of longterm synaptic depression in visual cortex by acetylcholine and norepinephrine. J Neurosci 19: 1599-1609.

Kitt CA, Hohmann C, Coyle JT, Price DL (1994). Cholinergic innervation of mouse forebrain structures. J Comp Neurol 341: 117-129.

Klink R, Alonso A (1997). Muscarinic modulation of the oscillatory and repetitive firing properties of entorhinal cortex layer II neurons. J Neurophysiol 77: 1813-1828. First study showing persistent spiking mechanisms induced by muscarinic receptor activation in entorhinal cortex.

Kohler CG, Martin EA, Kujawski E, Bilker W, Gur RE, Gur RC (2007). No effect of donepezil on neurocognition and social cognition in young persons with stable schizophrenia. Cogn Neuropsychiatry 12: 412-421.

Kopelman MD, Corn TH (1988). Cholinergic 'blockade' as a model for cholinergic depletion. A comparison of the memory deficits with those of Alzheimer-type dementia and the alcoholic Korsakoff syndrome. Brain 111: 1079-1110.

Kozak R, Bruno JP, Sarter M (2006). Augmented prefrontal acetylcholine release during challenged attentional performance. Cereb Cortex 16: 9-17.

Kozak R, Martinez V, Young D, Brown H, Bruno JP, Sarter M (2007). Toward a neuro-cognitive animal model of the cognitive symptoms of schizophrenia: disruption of cortical cholinergic neurotransmission following repeated amphetamine exposure in attentional task-performing, but not non-performing, rats. Neuropsychopharmacology 32: 2074-2086.

Kremin T, Hasselmo ME (2007). Cholinergic suppression of glutamatergic synaptic transmission in hippocampal region CA3 exhibits laminar selectivity: implication for hippocampal network dynamics. Neuroscience 149: 760-767.

Krnjevic K, Pumain R, Renaud L (1971). The mechanism of excitation by acetylcholine in the cerebral cortex. J Physiol 215: 247-268. First study showing that the enhancement of cortical spiking activity by acetylcholine arises from a decrease of membrane potassium conductances in cortical neurons.

Kukolja J, Thiel CM, Fink GR (2009). Cholinergic stimulation enhances neural activity associated with encoding but reduces neural activity associated with retrieval in humans. J Neurosci 29: 8119-8128.

Lambe EK, Picciotto MR, Aghajanian GK (2003). Nicotine induces glutamate release from thalamocortical terminals in prefrontal cortex. Neuropsychopharmacology 28: 216-225.

Lawrence JJ, Grinspan ZM, Statland JM, McBain CJ (2006a). Muscarinic receptor activation tunes mouse stratum oriens interneurones to amplify spike reliability. $J$ Physio/ 571: 555-562. This study shows muscarinic cholinergic receptor effects that enhance theta rhythmic firing selectively in one class of interneurons, in contrast to causing afterdepolarizations in a different class.

Lawrence JJ, Statland JM, Grinspan ZM, McBain CJ (2006b). Cell type-specific dependence of muscarinic signalling in mouse hippocampal stratum oriens interneurones. J Physiol 570: 595-610.
Lawson VH, Bland BH (1993). The role of the septohippocampal pathway in the regulation of hippocampal field activity and behavior: analysis by the intraseptal microinfusion of carbachol, atropine, and procaine. Exp Neurol 120: 132-144.

Lee MG, Chrobak JJ, Sik A, Wiley RG, Buzsaki G (1994). Hippocampal theta activity following selective lesion of the septal cholinergic system. Neuroscience 62: 1033-1047.

Leiser SC, Bowlby MR, Comery TA, Dunlop J (2009). A cog in cognition: how the alpha7 nicotinic acetylcholine receptor is geared towards improving cognitive deficits. Pharmacol Ther 122: 302-311.

Leung VL, Zhao Y, Brown TH (2006). Graded persistent firing in neurons of rat perirhinal cortex. Soc Neurosci Abstr 32: 636.618.

Levin ED, Conners CK, Silva D, Hinton SC, Meck WH, March J et al (1998). Transdermal nicotine effects on attention. Psychopharmacology (Berl) 140: 135-141.

Levin ED, McClernon FJ, Rezvani AH (2006). Nicotinic effects on cognitive function: behavioral characterization, pharmacological specification, and anatomic localization. Psychopharmacology 184: 523-539.

Little JT, Johnson DN, Minichiello M, Weingartner H, Sunderland T (1998). Combined nicotinic and muscarinic blockade in elderly normal volunteers: cognitive, behavioral, and physiologic responses. Neuropsychopharmacology 19: 60-69.

Lysakowski A, Wainer BH, Bruce G, Hersh LB (1989). An atlas of the regional and laminar distribution of choline acetyltransferase immunoreactivity in rat cerebral cortex. Neuroscience 28: 291-336.

Maclean KA, Aichele SR, Bridwell DA, Mangun GR, Wojciulik E, Saron CD (2009). Interactions between endogenous and exogenous attention during vigilance. Atten Percept Psychophys 71: 1042-1058.

Madison DV, Lancaster B, Nicoll RA (1987). Voltage clamp analysis of cholinergic action in the hippocampus. J Neurosci 7: 733-741.

Madison DV, Nicoll RA (1984). Control of the repetitive discharge of rat CA 1 pyramidal neurones in vitro. J Physiol 354: 319-331.

Marrosu F, Portas C, Mascia MS, Casu MA, Fa M, Giagheddu M et al (1995). Microdialysis measurement of cortical and hippocampal acetylcholine release during sleep-wake cycle in freely moving cats. Brain Res 671: 329-332. This study using microdialysis over long time intervals shows the change in overall acetylcholine release during different stages of waking and sleep.

Martin LF, Kem WR, Freedman R (2004). Alpha-7 nicotinic receptor agonists: potential new candidates for the treatment of schizophrenia. Psychopharmacology 174: 54-64.

McAlonan K, Cavanaugh J, Wurtz RH (2006). Attentional modulation of thalamic reticular neurons. J Neurosci 26: 4444-4450.

McGaughy J, Decker MW, Sarter M (1999). Enhancement of sustained attention performance by the nicotinic acetylcholine receptor agonist ABT-418 in intact but not basal forebrain-lesioned rats. Psychopharmacology 144: 175-182.

McGaughy J, Everitt BJ, Robbins TW, Sarter M (2000). The role of cortical cholinergic afferent projections in cognition: impact of new selective immunotoxins. Behav Brain Res 115: 251-263.

McGaughy J, Kaiser T, Sarter M (1996). Behavioral vigilance following infusions of 192 IgG-saporin into the basal forebrain: selectivity of the behavioral impairment and relation to cortical AChE-positive fiber density. Behav Neurosci 110: 247-265. The study demonstrated that selective removal of the cortical cholinergic input system drastically, selectively and persistently impaired cue detection in rats performing an attention task.

McGaughy J, Koene RA, Eichenbaum H, Hasselmo ME (2005). Cholinergic deafferentation of the entorhinal cortex in rats impairs encoding of novel but not familiar stimuli in a delayed nonmatch-to-sample task. J Neurosci 25: 10273-10281.

McGaughy J, Sarter M (1998). Sustained attention performance in rats with intracortical infusions of 192 lgG-saporin-induced cortical cholinergic deafferentation: effects of physostigmine and FG 7142. Behav Neurosci 112: 1519-1525.

McQuiston AR, Madison DV (1999a). Nicotinic receptor activation excites distinct subtypes of interneurons in the rat hippocampus. J Neurosci 19: 2887-2896.

McQuiston AR, Madison DV (1999b). Muscarinic receptor activity induces an afterdepolarization in a subpopulation of hippocampal CA1 interneurons. J Neurosci 19: 5703-5710.

McQuiston AR, Madison DV (1999c). Muscarinic receptor activity has multiple effects on the resting membrane potentials of CA1 hippocampal interneurons. J Neurosci 19: 5693-5702.

Mesulam M (2004). The cholinergic lesion of Alzheimer's disease: pivotal factor or side show? Learn Mem 11: 43-49. This review provides a balanced and informative account of the role of cholinergic cell loss in dementia.

Mesulam MM, Hersh LB, Mash DC, Geula C (1992). Differential cholinergic innervation within functional subdivisions of the human cerebral cortex: a choline acetyltransferase study. J Comp Neurol 318: 316-328. 
M'Harzi M, Palacios A, Monmaur P, Willig F, Houcine O, Delacour J (1987). Effects of selective lesions of fimbria-fornix on learning set in the rat. Physiol Behav 40: 181-188.

Miller EK, Desimone R (1993). Scopolamine affects short-term memory but not inferior temporal neurons. NeuroReport 4: 81-84.

Mitchell JF, Sundberg KA, Reynolds JH (2007). Differential attention-dependent response modulation across cell classes in macaque visual area V4. Neuron 55: 131-141.

Mizumori SJY, Barnes CA, McNaughton BL (1989). Reversible inactivation of the medial septum - selective effects on the spontaneous unit-activity of different hippocampal cell-types. Brain Res 500: 99-106.

Molchan SE, Martinez RA, Hill JL, Weingartner HJ, Thompson K, Vitiello B et al (1992). Increased cognitive sensitivity to scopolamine with age and a perspective on the scopolamine model. Brain Res Rev 17: 215-226.

Monmaur P, Collet A, Puma C, Frankel-Kohn L, Sharif A (1997). Relations between acetylcholine release and electrophysiological characteristics of theta rhythm: a microdialysis study in the urethane-anesthetized rat hippocampus. Brain Res Bull 42: $141-146$.

Muir JL, Dunnett SB, Robbins TW, Everitt BJ (1992). Attentional functions of the forebrain cholinergic systems: effects of intraventricular hemicholinium, physostigmine, basal forebrain lesions and intracortical grafts on a multiple-choice serial reaction time task. Exp Brain Res 89: 611-622.

Nelson CL, Sarter M, Bruno JP (2005). Prefrontal cortical modulation of acetylcholine release in posterior parietal cortex. Neuroscience 132: 347-359.

Newman LA, McGaughy J (2008). Cholinergic deafferentation of prefrontal cortex increases sensitivity to cross-modal distractors during a sustained attention task. J Neurosci 28: 2642-2650.

Newhouse PA, Potter A, Kelton M, Corwin J (2001). Nicotinic treatment of Alzheimer's disease. Biol Psychiat 49: 268-278.

Newhouse PA, Potter A, Singh A (2004). Effects of nicotinic stimulation on cognitive performance. Curr Opin Pharmacol 4: 36-46.

Nilsson OG, Shapiro ML, Gage FH, Olton DS, Bjorklund A (1987). Spatial learning and memory following fimbria-fornix transection and grafting of fetal septal neurons to the hippocampus. Exp Brain Res 67: 195-215.

Nissen MJ, Knopman DS, Schacter DL (1987). Neurochemical dissociation of memory systems. Neurology 37: 789-794.

Pang KC, Nocera R (1999). Interactions between 192-lgG saporin and intraseptal cholinergic and GABAergic drugs: role of cholinergic medial septal neurons in spatial working memory. Behav Neurosci 113: 265-275.

Pang KC, Nocera R, Secor AJ, Yoder RM (2001). GABAergic septohippocampal neurons are not necessary for spatial memory. Hippocampus 11: 814-827.

Paolone G, Ji J, Williams S, Howe WM, Ward J, Parikh V et al (2009). Effects of the selective alpha $7 \mathrm{nAChR}$ agonist ABT-107 on prefrontal glutamatergic and cholinergic activity and attentional performance. Society for Neuroscience Annual Meeting. Chicago, IL.

Parikh V, Ji J, Decker MW, Sarter M (2010). Prefrontal $\beta 2$ subunit-containing and $\alpha 7$ $n A C h R s$ differentially control prefrontal glutamatergic and cholinergic signaling. J Neurosci 30: 2518-3530.

Parikh V, Kozak R, Martinez V, Sarter M (2007). Prefrontal acetylcholine release controls cue detection on multiple timescales. Neuron 56: 141-154. The first study that employed enzyme-coated microelectrodes to monitor real-time acetylcholine release in performing animals and concluded that cholinergic transients mediated cue detection.

Parikh V, Man K, Decker MW, Sarter M (2008). Glutamatergic contributions to nicotinic acetylcholine receptor agonist-evoked cholinergic transients in the prefrontal cortex. J Neurosci 28: 3769-3780.

Parikh V, Pomerleau F, Huettl P, Gerhardt GA, Sarter M, Bruno JP (2004). Rapid assessment of in vivo cholinergic transmission by amperometric detection of changes in extracellular choline levels. Eur J Neurosci 20: 1545-1554.

Parikh V, Sarter M (2008). Cholinergic mediation of attention: contributions of phasic and tonic increases in prefrontal cholinergic activity. Ann NY Acad Sci 1129: 225-235.

Parrott AC (1986). The effects of transdermal scopolamine and four dose levels of oral scopolamine $(0.15,0.3,0.6$, and $1.2 \mathrm{mg})$ upon psychological performance. Psychopharmacology 89: 347-354.

Passetti F, Dalley JW, O'Connell MT, Everitt BJ, Robbins TW (2000). Increased acetylcholine release in the rat medial prefrontal cortex during performance of a visual attentional task. Eur J Neurosci 12: 3051-3058.

Patil MM, Hasselmo ME (1999). Modulation of inhibitory synaptic potentials in the piriform cortex. J Neurophysiol 81: 2103-2118.

Pazzagli A, Pepeu G (1965). Amnesic properties of scopolamine and brain acetylcholine in the rat. Int $J$ Neuropharmacol 4: 291-299.

Penetar DM, McDonough JH (1983). Effects of cholinergic drugs on delayed match to sample performance of Rhesus monkeys. Pharmacol Biochem Behav 19: 963-967.
Pepeu G, Giovannini MG (2009). Cholinesterase inhibitors and beyond. Curr Alzheimer Res 6: 86-96.

Perry E, Walker M, Grace J, Perry R (1999). Acetylcholine in mind: a neurotransmitter correlate of consciousness? Trends Neurosci 22: 273-280.

Petersen RC (1977). Scopolamine induced learning failures in man. Psychopharmacology 52: 283-289.

Phillips JM, McAlonan K, Robb WGK, Brown VJ (2000). Cholinergic neurotransmission influences covert orientation of visuospatial attention in the rat. Psychopharmacology 150: 112-116.

Pinault D (2004). The thalamic reticular nucleus: structure, function and concept. Brain Res Rev 46: 1-31.

Pitler TA, Alger BE (1992). Cholinergic excitation of GABAergic interneurons in the rat hippocampal slice. J Physiol 450: 127-142.

Posner Ml (1980). Orienting of attention. Quart J Expl Psychol 32: 3 \#\#.

Posner MI (2008). Measuring alertness. In: Pfaff DW, Kieffer BL (eds). Molecular and Biophysical Mechanisms of Arousal, Alertness, and Attention. Blackwell Publishing: Boston, MA, 1129: 193-199.

Posner MI, Rothbart MK (2007). Research on attention networks as a model for the integration of psychological science. Ann Rev Psychol 58: 1-23.

Posner MI, Snyder CRR, Davidson BJ (1980). Attention and the detection of signals. J Exp Psychol 109: 160-174. This and the other classic papers by Posner provide the conceptual framework for our interpretation of the attentional roles of the basal forebrain.

Potter A, Corwin J, Lang J, Piasecki M, Lenox R, Newhouse PA (1999). Acute effects of the selective cholinergic channel activator (nicotinic agonist) ABT-418 in Alzheimer's disease. Psychopharmacology (Berl) 142: 334-342.

Radcliffe KA, Dani JA (1998). Nicotinic stimulation produces multiple forms of increased glutamatergic synaptic transmission. J Neurosci 18: 7075-7083.

Raffaele KC, Asthana S, Berardi A, Haxby JV, Morris PP, Schapiro MB et al (1996). Differential response to the cholinergic agonist arecoline among different cognitive modalities in Alzheimer's disease. Neuropsychopharmacology 15: 163-170.

Rasch BH, Born J, Gais S (2006). Combined blockade of cholinergic receptors shifts the brain from stimulus encoding to memory consolidation. J Cogn Neurosci 18: 793-802.

Rasmusson DD, Smith SA, Semba K (2007). Inactivation of prefrontal cortex abolishes cortical acetylcholine release evoked by sensory or sensory pathway stimulation in the rat. Neuroscience 149: 232-241.

Robbins TW, Everitt BJ, Marston HM, Wilkinson J, Jones GH, Page KJ (1989). Comparative effects of ibotenic acid- and quisqualic acid-induced lesions of the substantia innominata on attentional function in the rat: further implications for the role of the cholinergic neurons of the nucleus basalis in cognitive processes. Behav Brain Res 35: 221-240. The first study that demonstrated that the basal forebrain neuronal system is necessary for attention.

Robbins TW, Mehta MA, Sahakian BJ (2000). Neuroscience. Boosting working memory. Science 290: 2275-2276.

Robbins TW, Semple J, Kumar R, Truman MI, Shorter J, Ferraro A et al (1997). Effects of scopolamine on delayed-matching-to-sample and paired associates tests of visual memory and learning in human subjects: comparison with diazepam and implications for dementia. Psychopharmacology (Berl) 134: 95-106.

Roberts AC, Robbins TW, Everitt BJ, Muir JL (1992). A specific form of cognitive rigidity following excitotoxic lesions of the basal forebrain in marmosets. Neuroscience 47: 251-264.

Roberts MJ, Thiele A (2008). Spatial integration and its moderation by attention and acetylcholine. Front Biosci 13: 3742-3759.

Roberts MJ, Zinke W, Guo K, Robertson R, McDonald JS, Thiele A (2005). Acetylcholine dynamically controls spatial integration in marmoset primary visual cortex. J Neurophysiol 93: 2062-2072. This study showed that local iontophoresis of acetylcholine into the visual cortex reduces the preferred length of cortical neurons, providing in vivo evidence for a reduction in spatial integration consistent with in vitro evidence for presynaptic inhibition of intracortical excitatory synapses.

Rogers JL, Kesner RP (2003). Cholinergic modulation of the hippocampus during encoding and retrieval. Neurobiol Learn Mem 80: 332-342.

Rogers JL, Kesner RP (2004). Cholinergic modulation of the hippocampus during encoding and retrieval of tone/shock-induced fear conditioning. Learn Mem 11: 102-107.

Rosier AM, Cornette L, Dupont P, Bormans G, Mortelmans L, Orban GA (1999). Regional brain activity during shape recognition impaired by a scopolamine challenge to encoding. Eur J Neurosci 11: 3701-3714.

Rusted JM, Caulfield D, King L, Goode A (2000). Moving out of the laboratory: does nicotine improve everyday attention? Behav Pharmacol 11: 621-629.

Rusted JM, Warburton DM (1992). Facilitation of memory by post-trial administration of nicotine: evidence for an attentional explanation. Psychopharmacology 108: $452-455$ 
Rye DB, Wainer BH, Mesulam MM, Mufson EJ, Saper CB (1984). Cortical projections arising from the basal forebrain: a study of cholinergic and noncholinergic components employing combined retrograde tracing and immunohistochemical localization of choline acetyltransferase. Neuroscience 13: $627-643$.

Sahakian BJ, Owen AM, Morant NJ, Eagger SA, Boddington S, Crayton L et al (1993). Further analysis of the cognitive effects of tetrahydroaminoacridine (THA) in Alzheimer's disease: assessment of attentional and mnemonic function using CANTAB. Psychopharmacology 110: 395-401.

Sarter M (2010). Attention. In: Stolerman I (ed). Encyclopedia of Psychopharmacology. Springer, Berlin, in press.

Sarter M, Bruno JP (1997). Trans-synaptic stimulation of cortical acetylcholine and enhancement of attentional functions: a rational approach for the development of cognition enhancers. Behav Brain Res 83: 7-14.

Sarter M, Bruno JP (2002). Mild cognitive impairment and the cholinergic hypothesis: a very different take on recent data. Ann Neurol 52: 384-385.

Sarter M, Bruno JP, Parikh V (2007). Abnormal neurotransmitter release underlying behavioral and cognitive disorders: toward concepts of dynamic and functionspecific dysregulation. Neuropsychopharmacology 32: 1452-1461.

Sarter M, Gehring WJ, Kozak R (2006). More attention must be paid: the neurobiology of attentional effort. Brain Res Rev 51: 145-160.

Sarter M, Nelson CL, Bruno JP (2005). Cortical cholinergic transmission and cortical information processing in schizophrenia. Schizophr Bull 31: 117-138.

Sarter M, Parikh V, Howe WM (2009a). Phasic acetylcholine release and the volume transmission hypothesis: time to move on. Nat Rev Neurosci 10: 383-390.

Sarter M, Parikh V, Howe WM (2009b). nAChR agonist-induced cognition enhancement: integration of cognitive and neuronal mechanisms. Biochem Pharmacol 78: 658-667.

Schon K, Atri A, Hasselmo ME, Tricarico MD, LoPresti ML, Stern CE (2005). Scopolamine reduces persistent activity related to long-term encoding in the parahippocampal gyrus during delayed matching in humans. J Neurosci 25: 9112-9123. This study shows that during the delay period of a delayed matching task, persistent activity appears that is correlated with subsequent memory for the sample stimuli and is blocked by the muscarinic receptor blocker scopolamine.

Schon K, Hasselmo ME, LoPresti ML, Tricarico MD, Stern CE (2004). Persistence of parahippocampal representation in the absence of stimulus input enhances long-term encoding: a functional magnetic resonance imaging study of subsequent memory after a delayed match-to-sample task. Neurosci 24: 11088-11097.

Schwindt PC, Spain WJ, Foehring RC, Chubb MC, Crill WE (1988). Slow conductances in neurons from cat sensorimotor cortex in vitro and their role in slow excitability changes. J Neurophysio/ 59: 450-467.

Shalinsky MH, Magistretti J, Ma L, Alonso AA (2002). Muscarinic activation of a cation current and associated current noise in entorhinal-cortex layer-II neurons. J Neurophysiol 88: 1197-1211.

Sheffler DJ, Williams R, Bridges TM, Xiang Z, Kane AS, Byun NE et al (2009). A novel selective muscarinic acetylcholine receptor subtype 1 antagonist reduces seizures without impairing hippocampus-dependent learning. Mol Pharmacol 76: 356-368.

Shirey JK, Brady AE, Jones PJ, Davis AA, Bridges TM, Kennedy JP et al (2009). A selective allosteric potentiator of the M1 muscarinic acetylcholine receptor increases activity of medial prefrontal cortical neurons and restores impairments in reversal learning. J Neurosci 29: 14271-14286.

Shirey JK, Xiang Z, Orton D, Brady AE, Johnson KA, Willians R et al (2008). An allosteric potentiator of M4 mAChR modulates hippocampal synaptic transmission. Nat Chem Biol 4: 42-50.

Silver MA, Shenhav A, D'Esposito M (2008). Cholinergic enhancement reduces spatial spread of visual responses in human early visual cortex. Neuron 60: 904-914. This study provides data from human imaging supporting the hypothesized role of muscarinic presynaptic inhibition of intracortical synaptic transmission in reducing the spatial spread of activity in visual cortex.

Stolerman IP, Mirza NR, Hahn B, Shoaib M (2000). Nicotine in an animal model of attention. Eur J Pharmacol 393: 147-154.

Sunderland T, Tariot PN, Cohen RM, Weingartner H, Mueller III EA, Murphy DL (1987). Anticholinergic sensitivity in patients with dementia of the Alzheimer type and age-matched controls. A dose-response study. Arch Gen Psychiatry 44: 418-426.

Sunderland T, Tariot PN, Newhouse PA (1988). Differential responsivity of mood, behavior, and cognition to cholinergic agents in elderly neuropsychiatric populations. Brain Res Rev 472: 371-389.

Suzuki WA, Miller EK, Desimone R (1997). Object and place memory in the macaque entorhinal cortex. J Neurophysiol 78: 1062-1081.
Tahvildari B, Fransen E, Alonso AA, Hasselmo ME (2007). Switching between 'On' and 'Off' states of persistent activity in lateral entorhinal layer III neurons. Hippocampus 17: 257-263.

Taly A, Corringer PJ, Guedin D, Lestage P, Changeux JP (2009). Nicotinic receptors: allosteric transitions and therapeutic targets in the nervous system. Nat Rev Drug Discov 8: 733-750.

Tang Y, Mishkin M, Aigner TG (1997). Effects of muscarinic blockade in perirhinal cortex during visual recognition. Proc Natl Acad Sci USA 94: 12667-12669. This study showed that local infusion of muscarinic blockers impaired the encoding of visual information for subsequent recognition.

Thiel CM, Fink GR (2008). Effects of the cholinergic agonist nicotine on reorienting of visual spatial attention and top-down attentional control. Neuroscience 152: 381-390.

Turchi J, Sarter M (1997). Cortical acetylcholine and processing capacity: effects of cortical cholinergic deafferentation on crossmodal divided attention in rats. Cogn Brain Res 6: 147-158.

Turchi J, Saunders RC, Mishkin M (2005). Effects of cholinergic deafferentation of the rhinal cortex on visual recognition memory in monkeys. Proc Natl Acad Sci USA 102: 2158-2161.

Valentino RJ, Dingledine R (1981). Presynaptic inhibitory effect of acetylcholine in the hippocampus. J Neurosci 1: 784-792.

Vogt KE, Regehr WG (2001). Cholinergic modulation of excitatory synaptic transmission in the CA3 area of the hippocampus. J Neurosci 21: 75-83.

Vossel S, Thiel CM, Fink GR (2008). Behavioral and neural effects of nicotine on visuospatial attentional reorienting in non-smoking subjects. Neuropsychopharmacology 33: 731-738.

Voytko ML, Olton DS, Richardson RT, Gorman LK, Tobin JR, Price DL (1994). Basal forebrain lesions in monkeys disrupt attention but not learning and memory. J Neurosci 14: 167-186.

Vuckovich JA, Semel ME, Baxter MG (2004). Extensive lesions of cholinergic basal forebrain neurons do not impair spatial working memory. Learn Memory 11: $87-94$

Walsh H, Govind AP, Mastro R, Hoda JC, Bertrand D, Vallejo Y et al (2008). Upregulation of nicotinic receptors by nicotine varies with receptor subtype. J Biol Chem 283: 6022-6032.

Warburton DM, Brown K (1971). Attenuation of stimulus sensitivity induced by scopolamine. Nature 230: 126-127.

Warburton DM, Mancuso G (1998). Evaluation of the information processing and mood effects of a transdermal nicotine patch. Psychopharmacology 135: 305-310.

Warburton EC, Koder T, Cho K, Massey PV, Duguid G, Barker GR et al (2003). Cholinergic neurotransmission is essential for perirhinal cortical plasticity and recognition memory. Neuron 38: 987-996.

Weese GD, Phillips JM, Brown VJ (1999). Attentional orienting is impaired by unilateral lesions of the thalamic reticular nucleus in the rat. J Neurosci 19: 10135-10139.

Wenk H (1989). The nucleus basalis magnocellularis Meynert (NbmM) complex-a central integrator of coded 'limbic signals' linked to neocortical modular operation? A proposed (heuristic) model of function. J Hirnforsch 30: 127-151.

Wesnes K, Simpson P, Kidd A (1988). An investigation of the range of cognitive impairments induced by scopolamine $0.6 \mathrm{mg}$ s.c. Hum Psychopharmacol 3: 27-41.

Wesnes K, Warburton DM (1984). Effects of scopolamine and nicotine on human rapid information processing performance. Psychopharmacology 82: 147-150.

Wienrich M, Ceci A, Ensinger HA, Gaida W, Mendla KD, Osugi T et al (2002). Talsaclidine (WAL 2014 FU), a muscarinic M1 receptor agonist for the treatment of Alzheimer's disease. Drug Develop Res 56: 321-334.

Wilens TE, Biederman J, Spencer TJ, Bostic J, Prince J, Monuteaux MC et al (1999). A pilot controlled clinical trial of ABT-418, a cholinergic agonist, in the treatment of adults with attention deficit hyperactivity disorder. Am J Psychiatry 156: 1931-1937.

Wilens TE, Decker MW (2007). Neuronal nicotinic receptor agonists for the treatment of attention-deficit/hyperactivity disorder: focus on cognition. Biochem Pharmacol 74: 1212-1223.

Wilens TE, Verlinden MH, Adler LA, Wozniak PJ, West SA (2006). ABT-089, a neuronal nicotinic receptor partial agonist, for the treatment of attentiondeficit/hyperactivity disorder in adults: results of a pilot study. Biol Psychiatry 59: 1065-1070.

Winson J, Abzug C (1977). Gating of neuronal transmission in the hippocampus: efficacy of transmission varies with behavioral state. Science 196: 1223-1225.

Winson J, Abzug C (1978). Neuronal transmission through hippocampal pathways dependent on behavior. J Neurophysiol 41: 716-732.

Witte EA, Marrocco RT (1997). Alteration of brain noradrenergic activity in rhesus monkey affects the alerting component of covert orienting. Psychopharmacoloy 132: 315-323. 
Woolf NJ (1991). Cholinergic systems in mammalian brain and spinal cord. Prog Neurobiol 37: 475-524.

Xiang Z, Huguenard JR, Prince DA (1998). Cholinergic switching within neocortical inhibitory networks. Science 281: 985-988.

Yamada M, Basile AS, Fedorova I, Zhang W, Duttaroy A, Cui Y et al (2003). Novel insights into M5 muscarinic acetylcholine receptor function by the use of gene targeting technology. Life Sci 74: 345-353.

Yamasaki M, Matsui M, Watanabe M (2010). Preferential localization of muscarinic M1 receptors on dendritic shaft and spine of cortical pyramidal cells and its anatomical evidence for volume transmission. J Neurosci 30: 4408-4418.

Yates SL, Bencherif M, Fluhler EN, Lippiello PM (1995). Up-regulation of nicotinic acetylcholine receptors following chronic exposure of rats to mainstream cigarette smoke or alpha 4 beta 2 receptors to nicotine. Biochem Pharmacol 50: 2001-2008.

Yoshida M, Hasselmo ME (2009). Persistent firing supported by an intrinsic cellular mechanism in a component of the head direction system. J Neurosci 29: 4945-4952.

Young BJ, Otto T, Fox GD, Elchenbaum H (1997). Memory representation within the parahippocampal region. J Neurosci 17: 5183-5195.

Young JW, Crawford N, Kelly JS, Kerr LE, Marston HM, Spratt C et al (2007). Impaired attention is central to the cognitive deficits observed in alpha 7 deficient mice. Eur Neuropsychopharmacol 17: 145-155.

Zaborszky L (2002). The modular organization of brain systems. Basal forebrain: the last frontier. Prog Brain Res 136: 359-372. This review provides a profoundly new view at the basal forebrain cholinergic system, focusing on multiple cell clusters in the basal forebrain and hitherto unknown, fine- topographic characteristics.

Zaborszky L, Buhl DL, Pobalashingham S, Bjaalie JG, Nadasdy Z (2005). Three-dimensional chemoarchitecture of the basal forebrain: spatially specific association of cholinergic and calcium binding protein-containing neurons. Neuroscience 136: 697-713.

Zaborszky L, Hoemke L, Mohlberg H, Schleicher A, Amunts K, Zilles K (2008). Stereotaxic probabilistic maps of the magnocellular cell groups in human basal forebrain. Neuroimage 42: 1127-1141.

Zikopoulos B, Barbas H (2006). Prefrontal projections to the thalamic reticular nucleus form a unique circuit for attentional mechanisms. J Neurosci 26: 7348-7361.

Zikopoulos B, Barbas H (2007a). Circuits for multisensory integration and attentional modulation through the prefrontal cortex and the thalamic reticular nucleus in primates. Rev Neurosci 18: 417-438.

Zikopoulos B, Barbas H (2007b). Parallel driving and modulatory pathways link the prefrontal cortex and thalamus. PLOS ONE 2: e848.

Zmarowski A, Sarter M, Bruno JP (2005). NMDA and dopamine interactions in the nucleus accumbens modulate cortical acetylcholine release. Eur J Neurosci 22: 1731-1740.

Zmarowski A, Sarter M, Bruno JP (2007). Glutamate receptors in nucleus accumbens mediate regionally selective increases in cortical acetylcholine release. Synapse 61: 115-123. 